\title{
Review
}

\section{Dementia-Friendly "Design": Impact on COVID-19 Death Rates in Long-Term Care Facilities Around the World}

\author{
Nancy L. Olson ${ }^{\mathrm{a}, *}$ and Benedict C. Albensi $\mathrm{i}^{\mathrm{a}, \mathrm{b}, *}$ \\ ${ }^{a}$ Division of Neurodegenerative Disorders, St Boniface Hospital Albrechtsen Research Centre, Winnipeg, \\ $M B$, Canada \\ ${ }^{\mathrm{b}}$ Department of Pharmacology \& Therapeutics, Max Rady College of Medicine, University of Manitoba, \\ Winnipeg, MB, Canada
}

Accepted 5 March 2021

Pre-press 25 March 2021

\begin{abstract}
Persons with dementia (PWD) make up a large portion of the long-term care (LTC) population the world over. Before a global pandemic swept the world, governments and healthcare providers struggled with how to best care for this unique population. One of the greatest challenges is a PWD's tendency to "walk with purpose" and exhibit unsafe wayfinding and elopement, which places them at risk of falls and injury. Past solutions included increased use of restraints and pharmacological interventions, but these have fallen out of favor over the years and are not optimal. These challenges put enormous strain on staff and caregivers, who are often poorly trained in dementia care, underpaid, overworked, and overstressed. PWD are impacted by these stresses, and unmet needs in LTC places an even greater stress on them and increases their risks of morbidity and mortality. The physical design of their environments contributes to the problem. Old, institutionalized buildings have poor lighting, poor ventilation, long dead-end hallways, poor visual cues, lack of home-like décor, shared bedrooms and bathrooms, and are often dense and overcrowded. These design elements contribute to the four 'A's' of dementia: apathy, anxiety, agitation, and aggression, and they also contributed to the rapid spread of COVID-19 in these facilities the world over. In this review, we present current "dementia friendly" design models in the home, community, and LTC, and argue how they could have saved lives during the pandemic and reduced the stresses on both the dementia resident and the caregiver/staff.
\end{abstract}

Keywords: Alzheimer's café, Alzheimer's disease, butterfly care, COVID-19, dementia, dementia friendly, dementia village, green care, green house, long-term care, wayfinding

\footnotetext{
*Correspondence to: Nancy Olson, BSc, RT, CRQM, Clinical Study Coordinator, Division of Neurodegenerative Disorders (DND), 351 Tache Ave./Lab 4050, Winnipeg, Manitoba R2H 2A6, Canada. Tel.: +1 2042353941 (lab); E-mail: nolson@sbrc.ca; Benedict C. Albensi, PhD, BCMAS, CRQM, Full Professor \& Manitoba Dementia Research Chair, University of Manitoba, Max Rady College of Medicine, Dept. of Pharmacology \& Therapeutics; Principal Investigator, St. Boniface Hospital Research, Everett Endowment Fund Chair (Alzheimer's research), Division of Neurodegenerative Disorders (DND), 351 Tache Ave./Lab 4050, Winnipeg, Manitoba R2H 2A6, Canada. Tel.: +1 204782 3698; E-mail: balbensi@sbrc.ca.
}

\section{INTRODUCTION}

COVID-19 especially impacted long-term care (LTC) facilities and generated a high death rate among persons with dementia (PWD). PWD are vulnerable to infectious diseases due to poor overall lung health and frailty, often compounded by chronic co-morbidities. PWD can account for $50 \%$ or more of all residents in LTC facilities worldwide [1-5]. If other cognitive impairments are included in the statistics (brain trauma, stroke, infectious disease), this number can increase to $80 \%$. LTC facilities are 
often large (>200 residents), crowded, under-staffed or poorly staffed, under-budgeted, and in old and poorly designed and ventilated buildings not created with dementia care, infection control, or crisis management in mind. Poor design elements can impact both staff and residents, increase stress, and reduce the overall quality of life (QoL) and quality of care (QoC) for PWD. During COVID-19, family and friends were often excluded from end-of-life visits and watched in grief and anger as their loved ones died alone, often on a ventilator, unable to say goodbye. These horrors have forced governments worldwide to ask: What went so wrong during this pandemic and what can we do to change the future of dementia care and housing so it never happens again? Although budget constraints and a lack of urgency have hindered extensive changes in the LTC model for decades, some cities, towns, and countries with government buy-in, have chosen to invest in "dementia-friendly" design at home, in the community, and in LTC. We examine some of these models worldwide and reflect how they impact the resident and staff in positive (and sometimes negative) ways and argue how they could have saved lives during COVID-19. We also examine some specific design elements (lighting, color and contrast, wayfinding and orientation, access to outdoor spaces) and look at how clever design changes to these elements (often at minimal cost) can have a positive impact on the health and well-being of residents and staff.

\section{LITERATURE REVIEW}

We performed a literature search using key words in combination (e.g., COVID-19, dementia, persons with dementia, Alzheimer's disease, dementia friendly, design, architecture, lighting, noise, wayfinding, elopement, long term care, nursing home, personal care home) and focused on those publications that focused on the triad of dementia care (resident, caregiver/staff, building) as they related to PWD in LTC, and COVID-19. References cover twenty years (2000-2020) and include systematic reviews (4), reviews (40), research articles (11), global and other reports (14), along with research letters, perspectives, editorials, commentaries, and correspondence. Grey literature includes web sites, policy briefs, government documents, architecture design guidelines, slide presentations, and book chapters. Search engines included Google, PubMed, Medline, and Cochrane Library.

\section{DEFINITIONS}

"Dementia" is an umbrella term that applies to people with cognitive impairment and behavioral changes $[6,7]$. Dementia can interfere with the ability of people to maintain the activities of daily living, which include eating, bathing, showering, toileting, and dressing [8-10]. More than 55 different illnesses can cause dementia, with Alzheimer's disease (AD) accounting for 50-70\% of all cases [11]. Other forms of dementia include vascular dementia, Lewy body dementia, frontotemporal dementia, and mixed dementia [8]. Parkinson's disease and other diseases can also lead to dementia, as can infectious diseases in rare instances [11]. The most common symptoms of dementia include memory impairment and at least one of the following cognitive disturbances: aphasia (impairment of language affecting the production or comprehension of speech and the ability to read and write), apraxia (inability to perform learned movements on command), and agnosia (inability to interpret sensations and hence to recognize things) [12].

"Long-Term Care" (LTC) refers to those facilities that provide continual, uninterrupted nursing care to patients unable to cope by themselves in their home or community. Worldwide, different terms define these types of facilities, including nursing homes, personal care homes, convalescent homes, rest homes, skilled nursing facilities, homes for the aged, geriatric nursing centers, care homes, and aged care homes $[13,14]$. In China, the demand for formal LTC has emerged only recently due to the migration of youth from rural to urban centers and the reduction in family size, which reduces the pool of caregivers. There is no standardized name for these Chinese facilities, and a myriad of terms have emerged including old age home, retirement apartment, residential care facility, welfare institute, and geriatric hospital [5]. LTC employs healthcare staff responsible for providing medical care (physical, mental, emotional), nutrition, religious/cultural care, community engagement, and transportation.

"COVID-19" is the disease caused by the novel coronavirus (SARS CoV-2), first identified in Wuhan, China in December 2019 [15-17]. COVID-19 was declared a global pandemic by the World Health Organization (WHO) on March 11, 2020, while affecting 113 countries and territories [18]. Its symptoms range from asymptomatic carriage to severe respiratory and multi-organ involvement and death. The incubation period can range from 1-14 days 
(median 5-6 days) from exposure to onset of symptoms $[15,19]$. The virus appears to spread by respiratory droplets, close personal contact, and touching surfaces with live virus, although all of these transmission possibilities are being actively investigated for their significance [15]. Even though the WHO and Centers for Disease Control (CDC) indicate that Coronaviruses do not typically spread in water and ventilation systems, this is being disputed by researchers who have studied older HVAC and ventilation systems, and aerosol transmission is now being considered a possible source of exposure $[16,20]$.

\section{PRE-COVID-19 DEMENTIA CARE}

Dementia presents distinctive issues within the LTC system because of its high prevalence, progressive nature, effects on behavior and ability to self-manage care due to impaired cognitive and decision-making capabilities, frequency of care transitions, risk of elder abuse, high rate of comorbid health conditions, heavy reliance and resulting impact on caregivers, and higher cost of dementia-specific LTC services compared to other chronic conditions late in life [21].

Institutionalized care (whether funded by public, private, or non-profit models) involves a triad of components that make this care model function. These include: 1) the dementia resident; 2) the dementia caregiver/staff; and 3) the building that houses the residents and caregiver/staff. Pre-COVID-19, these three components, when studied separately, presented unique challenges and concerns.

\section{The pre-COVID-19 dementia resident}

PWD represent $50 \%$ or more of the LTC population globally. The vast majority of families would prefer to keep their loved ones at home until their end of life; however, this is not always possible. The type and location of LTC facility PWD are placed into, and the timing of that placement can vary depending on who is involved with the decision (spouse, child, grandchild, other relative) [22], as well as family dynamics, cultural behavior, and accessibility to medical services; however the reasons for that placement are often similar around the world and include:

\section{Caregiver burden}

There is an assumption that caregiver "stress" (depression, feelings of being overwhelmed) are the main reason for the institutionalization of a loved one, though that is not necessarily the case [23]. In fact, other burdens besides stress may be better indicators of whether a person places a family member into LTC, including cognitive impairment, prior hospital admissions, co-morbidity, and polypharmacy [23, 24]. In a U.S. report by Buhr et al. in 2006, reasons for placement in LTC included: 1) the need for more skilled care $(65 \%) ; 2)$ the caregivers' health $(49 \%) ; 3)$ the patients' dementia-related behaviors (46\%); and 4) the need for more assistance (23\%) [25]. Caregivers reporting a greater burden were more likely to institutionalize their loved ones than those caregivers that reported greater positive aspects to caregiving [26].

\section{Dementia stigma}

The word 'stigma' originates from the Greek language and means a 'mark' or 'brand' [27]. Stigma can be defined as "spoiled identity" or of persons being negatively labeled, a loss of status and power, discrimination, and stereotyping [28]. During a 2014 Alzheimer's Disease International Conference "Dementia: Working Together for a Global Solution", the terms used by researchers and presenters to describe PWD were often derogatory and disrespectful, and included terms such as 'demented', 'sufferers', 'subjects', 'victims', and 'not there at all'. These types of stigma affect how and when a general practitioner diagnoses PWD, and how the public and caregiver approach and treat them [28]. At the professional level, stigma can lead to differential or delayed diagnosis or treatment, and at a societal level, it can lead to differential access and use of services and increased institutionalization $[29,30]$. The delay in diagnosis affiliated with stigma often means that PWD are already at a moderate to late stage of dementia at the time of institutionalization, which can affect their level of stress and behavior upon entrance into LTC facilities [30].

Once PWD are institutionalized, away from home in unfamiliar surroundings, they face a myriad of challenges and barriers that can place them at risk and increase their stress. These challenges and risks include pain management, malnutrition and dehydration due to a diminished capacity to recognize hunger and thirst, risk of falls, unsafe wayfinding (unattended wandering), elopement (unattended exit), and impaired judgement, which places them at a higher risk of restraint usage [11]. Institutionalized PWD are at a higher risk of falls and sleep disturbances, which can lead to functional decline, impairment, social disengagement, frailty, agitation, disability, and death [31-33]. 


\section{The pre-COVID-19 dementia caregiver (staff)}

Job descriptions for LTC staff vary around the world, but may include doctors, nursing directors, LTC facility directors, floor nurses, nurse practitioners, gerontology specialists, healthcare aides, nursing assistants, nurses' aides, medication aides/ technicians, personal care or support workers, orderlies, social workers, physiotherapists, recreational therapists, occupational therapists, as well as kitchen, laundry, maintenance, and housekeeping staff [34, 35]. For direct care providers, educational and training requirements can range broadly from minimal requirements to extensive training. In the U.S., the federal government mandates that all direct caregivers receive 75 hours of training before being certified to work in Medicaid/Medicare certified Nursing Homes, whereas Germany requires at least $50 \%$ of all care staff are Registered Nurses who have had a three-year geriatric training program [5]. In Canada, however, unregulated workers (no independent accountability, no recognized education and training standards) provide up to $90 \%$ of direct patient care, more than $90 \%$ are women, $70 \%$ are over 40 , and $60 \%$ speak English as a second language [2,34]. In China, where LTC is an emerging concept, 70\% of Nursing Home administrators only had junior high school degrees, and for direct caregivers, $76 \%$ of them were illiterate or only had primary school education [5]. Common staffing problems in LTC worldwide include poor dementia-specific training, relegation of most jobs to women (often immigrant women), low pay, poor benefits, stressful working conditions, high rates of on-the-job injury, and fewer opportunities for advancement and development, which leads to job dissatisfaction and high turnover [2, 4, 29, 34-36]. Gaps in training have been identified in many countries and policies are now being developed to provide training unique to dementia care. In the U.K., nurses often felt frustrated and overwhelmed by dementia care and felt they did not possess the practical skills to implement the necessary psychosocial interventions required to care for PWD [37]. In other instances, poor training was found to impact the way staff behaved towards residents [35].

It is estimated that only $10 \%$ of residents' symptoms in LTC are caused by the dementia itself with the other $90 \%$ resulting from the quality of care PWD receive [12]. In 1991, Dr. Bill Thomas, a Harvardeducated physician, defined the "three plagues" of nursing homes: boredom, loneliness, and helplessness [34]. Dementia residents often feel neglected by LTC staff who are over-worked and unable to provide the type of targeted care required. Although basic food and accommodation needs are met in LTC, unmet needs reported by dementia patients include lack of stimulating daytime activities and social company, lack of support to help cope with psychological distress (depression and anxiety), and poor assistance with memory, eyesight, and hearing problems [12]. When PWD were interviewed in Norwegian LTC facilities about their QoL, they often complained that staff walked into their rooms without knocking (lack of privacy), they were not treated by some staff in a way they approved (i.e., treated as a brat, overhandled), and staff disappeared and left residents alone in living rooms and corridors [38].

\section{The pre-COVID-19 LTC building}

The Institutional-based "environment of care" (EOC) has contributed to resident's agitation and restlessness [39]. LTC facilities are not designed with PWD in mind and are often crowded, have shared bedroom and bathroom facilities, and allow gathering in common areas [40]. Building standards in current facilities may be decades old, and can include fourperson shared wards and communal dining rooms where hundreds of residents are brought down to dine together [40]. For-profit homes tend to have a lower proportion of single-occupancy rooms and older design standards than not-for-profit homes [41]. The larger the LTC facility (>30 residents), the more agitation, aggression, intellectual deterioration, and emotional disturbance and the more frequent territorial conflicts/space invasion issues arise in PWD [42]. Spatial design, unnatural lighting, high noise levels, long dead-end hallways, poor color contrasts, lack of privacy, glare off floors, lack of access to outdoor spaces, and the lack of homelike décor and visual cues, all affect the long-term QoL for PWD $[42,43]$.

\section{COVID-19 SPECIFIC DEMENTIA CARE}

By September 2020, in twelve Organization for Economic Co-operation and Development (OECD) member countries, mortality rates from COVID-19 among LTC residents, on average, was 644-fold higher than for community-dwelling younger persons [44]. COVID-19 death rates in LTC as a \% of total deaths ranged from 19-72\% by November 2020 [45]. The triad of components discussed previously 
all aligned in ways that created an unprecedented disaster, and in some countries, the generational loss of their population will be felt for decades to come. When each component of the PWD care model is examined, the negative impact of COVID-19 is not surprising.

\section{The COVID-19 dementia resident}

Co-morbidities such as diabetes, cardiovascular disease, chronic respiratory disease, cerebrovascular disease, malignancy, and dementia were proved to independently increase the risk of COVID-19 progression, severe outcomes, and death [45]. Early on in the COVID-19 outbreak, evidence showed a high prevalence of dementia among COVID-19 patients with the rate of dementia in hospitalized cases of COVID-19 ranging from $6.8-13.1 \%$, and, in addition, case fatality of COVID-19 was significantly higher in the elderly with dementia $[1,46]$. In Italy early in the pandemic, the mortality rate in dementia patients with COVID-19 was $62.2 \%$ compared to $26.2 \%$ in patients without dementia [1, 46]. In South Korea, $\mathrm{AD}$ and chronic lung disease were predictive factors for death from COVID-19, especially after the age of 70 [22].

This high rate of COVID-19 infection among PWD could be partially explained by frailty, aging, and chronic comorbidities, particularly cardio- or cerebrovascular diseases [1]. In addition, the $A P O E$ $\varepsilon 4$ allele (a gene affiliated with dementia) is associated with severe COVID-19 infection [1, 47]. $A P O E \varepsilon 4$, which is known to exacerbate microgliamediated neuroinflammation and neurodegeneration and increase macrophage production of cytokine, may augment COVID-19 severity by impacting the host immune response [47]. Individuals with dementia are more likely to have cardiovascular disease, diabetes, and pneumonia, all of which put them at higher risk of acquiring COVID-19 in LTC $[18,45]$. In China early in the pandemic, 90\% of COVID-19 patients had pneumonia, and mortality from pneumonia has been reported to be twice higher in individuals with dementia compared to those without dementia, even prior to the pandemic $[18,48]$. Even with multiple co-morbidities, however, one of the reasons given for a high death rate in PWD with COVID-19 included early "asymptomatic" carriage or a lack of typical symptoms. COVID-19 patients with dementia often presented with non-respiratory symptoms such as delirium (particularly the hypoactive form) or isolated functional decline in the absence of any obvious physical symptoms, along with pyrexia and diarrhea $[1,47,49]$. During the pandemic, PWD have faced a "double burden" due to their increased morbidity and mortality and the breakdown of their social supports $[1,50]$. One of the first responses to COVID-19 in LTC was to "shut the doors" and eliminate all family visits. This loss of familiar contact has caused much stress in the dementia population. While social distancing, isolation, and safeguard procedures are the most effective approach to COVID-19 infection in LTC, this approach can endanger the safety of dementia residents and increase the risk of cardiovascular disease, obesity, and stroke, and correlates with anxiety, depression, and cognitive decline [50]. A lack of physical closeness has increased the level of loneliness, depression, and stress, reduced the amount of exercise, disrupted sleep patterns, increased delirium, and have caused trauma which may lead to further cognitive decline, all of which have increased the risk of morbidity and mortality in PWD in LTC [18]. Lack of formal and informal support during COVID-19 may further endanger the lives of PWD due to risk of falls, aspiration pneumonia, and even suicide [1]. Loneliness was already more prevalent in LTC institutions than the community prior to COVID-19 (22-42\% versus 10\%), and loneliness has been associated with deleterious consequences, including depression, alcoholism, suicidal thoughts, aggressive behaviors, anxiety, and impulsivity [51]. Since COVID-19, some LTC residents have had more symptoms of depression and suicidal thoughts, and more have complained of weakness and muscle atrophy and had more falls $[52,53]$. All of these factors increase their susceptibility to infectious agents such as COVID-19.

\section{The COVID-19 dementia caregiver (staff)}

LTC staff worldwide were overwhelmed when COVID-19 swept through their facilities. Some of the reasons for this included a rapid spread of positive cases due to high patient density, as well as poor ventilation and communal living conditions (shared bedrooms and bathrooms, common eating areas, single elevators). Other reasons included a lack of infection control and dementia-specific knowledge and training, lack of pandemic and crisis preparedness and strategic planning, poor COVID-19 testing and surveillance guidelines, poor working conditions including insufficient staffing levels and staffing mix, a lack of personal protective equipment (PPE) such as oxygen, ventilators, masks, and eye shields, a lack 
of screening resources for symptoms, travel history and contacts, and the poor physical design of their facilities [2, 40, 41, 54-61]. These conditions exacerbated an already stressful situation, and many staff got infected or stayed home to prevent getting infected, threatened to quit, or quit outright [1,2]. Even when Infection Prevention and Control (IPC) guidelines for respiratory infections were in place, staff found them complicated and constantly changing, and felt a lack of communication and support from managers as well as a lack of IPC training, lack of physical space for isolation and lack of access to and trust in PPE [62]. Pandemic and disaster contingency planning in LTC (which should involve political commitment and strict monitoring processes) was found to be lacking in China and Italy early in the pandemic [63]. Staff themselves were often the vectors of infection, due to working part-time in multiple facilities due to poor pay and lack of benefits (e.g., sick time), increasing the likelihood of spread of infection to residents and staff $[2,14,18,47,60,64]$. In the U.K., each resident receives between 3.1 and $4.8 \mathrm{~h}$ of direct care per day normally, dependent on most residents spending significant time in common areas [49]. Managing residents in isolation in bedrooms during COVID-19 presented challenges to staff and placed residents at risk of falls and injury due to lack of supervision [49]. Staffing shortages, lack of training, and lack of resources during COIVD-19 led to restrictive interventions and placed all residents at increased risk of falls, injury, stroke, deconditioning, skin breakdown, blood clots, and death [65]. In one case study in Canada, a dementia patient who tested negative for COVID-19 was told to isolate for 14 days in her room; math problems, coloring pages, and movies and music on a tablet were provided to keep the resident occupied. However, because the door could be opened from the inside, and the resident was strong and of large size, staff could not keep her contained to her room, and often ended up confronting the individual without time to don proper PPE. In this case, pharmacological measures (use of a more sedating agent) and physical restraints (a geriatric recliner using a pelvic holder) were used, although this is not a preferred option [65]. This case demonstrates the unique challenges to staff during COVID-19, who had to deal with both sick and healthy residents while short staffed, under extreme conditions of stress, facing the loss of residents on a daily basis, and concerned for the wellbeing of themselves and their loved ones at home.

\section{The COVID-19 LTC building}

COVID-19 can remain stable in airborne aerosols for at least $3 \mathrm{~h}$ and persist on some surfaces for days [58]. Most LTC facilities do not have airborne infection isolation rooms, which are under slight negative pressure with respect to adjacent rooms and hallways and thus are not designed for infection control practices $[2,58]$. Forced flow air ventilation systems are found in most institutional LTC facilities [39]. In these systems, both cold and hot air are pushed through ceiling grills, which often creates breezes on residents, and despite exchange rates which follows building codes, the air is circulated throughout the entire building so if one resident is sick, their germs can spread through the entire ventilation system [39]. In one European study, the effect of air quality and ventilation in 50 nursing homes in seven countries was evaluated in 600 elderly nursing home residents [66]. Only $19 \%$ of the residents had adequate ventilation, and poor air quality and exposure to indoor air pollutants in these LTC facilities exacerbated respiratory symptoms in elderly residents, with frailty increasing with age [66]. Recommendations during COVID-19 included placing patients in isolation alone or having them share rooms with known COVID-19 positive patients and leaving the door closed [58]. This is difficult to accomplish with PWD who are prone to open doors and wander (commonly called "walk with purpose") [54]. Crowding, shared bathroom facilities, and gathering in common areas are a result of design flaws that have been linked to the rapid spread of COVID-19 in LTC facilities [67]. In Canada, most LTC buildings were built between 1950 and 1990 and many of these facilities remain at 1972 building standards (called C standard) and still include four-person shared wards and large communal dining rooms [2, 40]. The oldest buildings tend to be larger (200-400 residents), with narrow hallways, crowded nursing stations, lack of outdoor spaces, and limited areas for staff and families away from resident rooms, all of which contributed to the challenges of dealing with COVID-19 [2]. Sharing a washroom means more opportunity to spread the virus among residents, and make staff less likely to wash their hands between patients [40]. Overall, the institutionalized design of older LTC facilities around the world have had a direct impact on the spread of COVID-19 and subsequent death rate and have placed the emphasis on what the design of future dementia care and housing should look like. 


\section{THE FUTURE OF POST-COVID-19 DEMENTIA CARE}

Future dementia care must take the triad of care (resident, caregiver/staff, building) into account, as each component must work together to make the model work. PWD are a unique population, and COVID-19 has taught us that their future long-term care must improve and requires innovative thinking, better contingency planning for infectious disease outbreaks and other disasters, and buy-in from governments, shareholders and private institutions that fund these LTC models. If PWD can remain at home or in the community without "institutionalizing" them, they would have less disorientation, confusion, and anxiety associated with new environments [68]. Reduced stress in PWD can lead to a reduction in medication use, reduced falls and hospital admissions, healthier residents, and healthier staff/caregivers [68]. Much work has been done worldwide to conceptualize and design dementiafriendly communities and dementia-friendly LTC models that improve the outcomes for PWD and their families and communities, as well as reduce cost, improve caregiver satisfaction and extend the QoL. We examine some of those models and evaluate how the triad of dementia care (resident, caregiver/staff, building) can work together to improve outcomes. We review two types of models: a non-nursing community model and a nursing LTC model. Which model a PWD ends up in is influenced by level of care required, cost, caregiver requirements, cultural stigma, family involvement, proper diagnosis, and a myriad of other factors.

\section{Dementia-friendly communities (DFC) (non-nursing model)}

The term "dementia friendly" (which differs from "age-friendly") may vary, but generally refers to the "social" health of PWD versus their "medical" health $[69,70]$. Defining attributes of dementia friendly include empowerment, aspiration, self-confidence, contribution, participation, meaningful activities, wayfinding ability, sense of safety, accessibility to local facilities, social acceptance and human rights [69]. Alzheimer's Disease International (ADI) states that Dementia Friendly Communities (DFC) "not only seek to preserve the safety and well-being of those living with dementia, but also empower all the members of the community to celebrate the capabilities of persons with dementia, and view them as valuable members of the towns, cities, villages and countries in which they reside." [70].

Across the world, $70 \%$ of PWD live in the community (not LTC institutions) and must alone face the stigma and social and cultural isolation that accompany such a diagnosis [71]. The vast majority of PWD globally have no formal diagnosis, and thus have no access to information, support, care, and treatment [71]. Increased awareness and understanding of dementia, increased social and cultural engagement, legal protection of PWD, increased capability of health and care services to respond to PWD needs, and improvements in physical environments (homes, residential care, hospitals, LTC, public places) are required for the DFC model to work [71, 72]. The most successful models internationally use two layers of networks/consultations: 1) A "bottoms-up" approach in which the PWD are directly involved in decision-making and design, and directly engage with their community; and 2) A "top-down" approach where governments and institutions (banks, healthcare organizations) help design and fund a DFC [34, 71-73]. DFC involve the following: 1) People (PWD, paid or unpaid caregivers); 2) Communities (social environment, physical environment); 3) Organizations (e.g., Alzheimer's and dementia-specific societies, healthcare organizations); and 4) Partnerships (ministers, government, businesses, consumer groups, social organizations) [69, 71]. Dementia Alliance International, a non-profit organization run effectively by PWD, states that "being dementia friendly is less about being 'friendly' and more about accessible communities and human rights" [71]. Following are examples of DFC initiatives around the world that have focused on "home" and "community" as the central component and have worked within the available infrastructure.

\section{The British Standards Institute "Code of practice for the recognition of dementia-friendly communities in England"}

In July 2015, the British Standards Institute in collaboration with The Alzheimer's Society (U.K.) and the Department of Health published the "Code of practice for the recognition of dementia-friendly communities in England" with the aim of signing up 20 cities, towns, and villages by 2015 . There are currently 137 communities in England and Wales, with a U.K.-Northern Ireland section as well $[68,74]$. This makes the U.K. one of the most progressive countries in the world for DFC initiatives. Some of these initiatives include: The York Initiative (an alliance 
of 50 organizations including local care and dementia branches, The City of York Council, and local business and transport), The Creative Spaces project in Cornwall (improves outdoor activities including fishing and woodland skills), the dementia-friendly swimming project, the Liverpool Dementia Action Alliance focus on dementia-friendly transport, and The Purple Angel campaign in Torbay in Devon initiated in January 2012, in which local groups and businesses take dementia-specific training and receive a Purple Angel badge [74]. The 800-year-old city of Liverpool is a great example of adapting and improving the available infrastructure to make the community more dementia-friendly. The concept of co-design, micro- and macro-scale design and "living lab" has been applied to the Liverpool model, and include some of the following initiatives:

Micro scale changes (home). The current Liverpool housing stock (mostly $19^{\text {th }}$ century terraced dwellings) can be adapted to include ground-level thresholds, small pet-friendly garden spaces with seating, raised garden beds, "safe home" technology (e.g., flood, smoke and carbon monoxide detectors, shut-off devices, talking phones and microwaves, rest easy products), accessible toilets, baths, and showers, open kitchen/dining areas, improved lighting, handrails, colors and textures that reduce confusion and anxiety, continuous floor finishes with no trip hazards, and hobby spaces for craft, reading, and music [68].

Macro scale changes (community). Community changes can include private and public trees, legible gardens that address the senses of smell, touch, sight, taste, and hearing, outdoor seating that is comfortable and easy to distinguish, access to public transport, integrated library and reading clubs, nearby medical facilities, churches, shopping centers, and memory centers that include spatial components of the past and future, smooth demarked pavement, nonintrusive public parking, good street lighting, clear signage, and use of color [68].

\section{The Netherlands Alzheimer's Café}

The "Alzheimer's Café" (or "Memory Café") was first introduced in the Netherlands by Dr. Bere Miesen, a Dutch Clinical Old Age Psychologist, in 1997, which pre-dates most global dementia-friendly initiatives [75]. It shares the same aim of other DFC initiatives, including reducing stigma, encouraging social engagement, and empowering PWD and their caregivers [69, 75]. Like other community-based initiatives, its intent is to keep PWD at home in the community as long as possible and provide a healthy outlet for both the dementia resident and caregiver. The aim is to provide a friendly, accessible location where PWD and caregivers can meet to share stories and experiences, and support each other, and is open to others with an interest in dementia including students, local politicians, and media [75]. There are currently 230 cafes in the Netherlands with 35,000 unique visitors per year. These cafes have been adopted in more than 15 countries around the world including Argentina, Aruba, and Curaçao where broader DFC initiatives do not yet exist, as well as Canada and the U.S. [75]. Although they do not involve a nuts-and-bolts physical adaptation to a community, they are important in stigma reduction and social support, an important first step to the implementation of any DFC initiative [75].

\section{The Dementia-Friendly Japan Initiative (DFJI)}

Japan's approach to creating dementia-friendly communities is inspiring for its involvement of PWD in decision-making and a person-centered approach [76]. In 2004, the Japanese Government changed the word "dementia" (Chiho) to "cognitive disorder" (Ninchi-sho) to reduce the stigma associated with it, similar to recent name changes in the Diagnostic and Statistical Manual of Mental Disorders, Version Five (DSM V). The DFJI, launched in 2013, is led by PWD and their caregivers who partner with local government, private enterprises, academia, and non-profit organizations [76]. This DFJI initiative was adopted by Britain, Wales, and Northern Ireland, and has now been replicated in Australia, Canada, India, Indonesia, Ireland, Netherlands, Scotland, and Sri Lanka [76]. In 2015, Japan also launched the "Orange Plan", a comprehensive package of measures to tackle dementia ranging from specialized medical staff and development of new drugs, to regular home visits, and support for family visits [77]. This plan to develop "Dementia Towns" (such as Matsudo, Japan) involves public awareness training for businesses such as banks and taxi drivers and the development of cafes and drop-in centers for PWD and their caregivers. For attending a 90-min lecture on dementia awareness, orange bracelets are provided. Volunteers with orange bibs walk neighborhoods with leaflets containing dementia specific information and will report suspicious circumstances (wandering residents, newspapers piling up outside homes, inappropriate behavior) to authorities [77]. Long before government initiatives, Sanada in Ueda City and Uji City began developing public awareness, 
support, and training programs in the 1990s, all of which encouraged PWD to remain involved in their communities and take part in policy development [76].

\section{The "Ibasho café" community initiative}

"Aging is not an individual issue. It is a societal issue" [78]. These are the words of Emi Kiyota, who helped build the first Ibasho café (Honeywell Ibasho House in Ofunato) in Japan in 2013 [78]. Though not specific to PWD, this model places elders at the heart of all design decisions and encourages those with disabilities and dementia to visit cafes and contribute to community projects in any way possible. The focus is on creating a physical and social infrastructure that empowers elders, reduces social isolation, and fills the gap between home and institution [78, 79]. It bases its concept on the fact that hundreds of residents in institutionalized care can be just as lonely as a single elder living at home.

\section{Other global DFC initiatives}

Most continents in the world have some countries involved in at least the early stages of DFC design and implementation [80] and include: Africa (Ghana, Namibia, Nigeria, Zimbabwe); South America (Argentina, Brazil); Central America (Costa Rica); North America (Canada, U.S.); Asia (Japan, Bangladesh, China, Hong Kong, India); Europe (U.K., Northern Ireland, Belgium, Germany, Greece); and Australia [80]. Some specific examples include Boston, Massachusetts in the U.S., New Westminster, British Columbia in Canada, Leeds in the U.K., and Western Australia [70]. These initiatives involve community education and public awareness in hospitals and schools, training of domestic and professional caregivers, the production of handbooks and dementia-specific training materials, and collaborations with national dementia-specific associations $[72,80]$. The intent of these initiatives is to change the future mindset of communities and be a precursor to the development of DFC [80].

\section{Dementia-friendly LTC (nursing model)}

If PWD can no longer remain in their home or community, their institutionalization should not have to include old, large, sterile, over-crowded buildings with poor design and layout, poor air quality, shared bedrooms and bathrooms, and lack of color, poor lighting, and unfriendly surfaces.
Small-scale dementia-friendly care models have emerged the world over that address the unique needs and challenges of dementia residents, and consider the long-term mental, physical and psychological health of both the resident and the caregiver/staff. In Table 1, we summarize how each LTC nursing model described below relates to the triad described previously (dementia resident, caregiver/staff and building).

\section{De Hogeweyk, The Netherlands (the "Dementia Village" Model)}

This world-renowned, mainly publicly funded dementia village was built on 4 acres of land in Weesp, The Netherlands in December 2009 at a cost of $€ 19.3$ million (U.S. \$27 million) [81-84]. It contains 27 homes with 6-7 residents per home, 17 designs, $\sim 170$ residents with severe dementia and 250 full- and part-time staff (geriatric nurses, specialists) who work in the village and hold a myriad of occupations (grocery-store attendees, cooks, and waiters).

The "Model" is based on 7 pillars: 1) favorable surroundings, which include a house with front door, living room, kitchen, bedroom, homey furniture, outdoor space, daily activities, and access to a supermarket, restaurant, café, hairdresser, theatre as well as gardens, squares, alleys, streets, and lanes; 2) life's pleasures and meaning of life, which involves a social life, including access to 35 different clubs, walks, daily shopping, day trips, and theatre; 3) health, which focuses on QoL, well-being, and social-relational, rather than medical, programs; 4) lifestyle, which is defined as surrounding, environment, interior design, social behavior, daily routines, preparation of meals, and norms and values; 5) employees, volunteers, and family, who understand the vision and apply it to their work. Employees consist of professional caregivers and assistants who provide 24/7 care and volunteers who work under a direct supervisor; 6) the organization, where policy is centered on the resident and living a normal life, and health; and 7) emancipation and inclusion, a recently added pillar which involves freedom from stigma and inclusion, along with being understood, respected, and supported $[82,85]$. Staff aim to enable people to "live until they die" and there is no sign of dementia as a form of "social death" [81]. The 17 designs assigned to the homes are based on which lifestyle the residents of that home adopt. Residents with similar personalities and interests live and eat together in the same home, to reduce stress and 


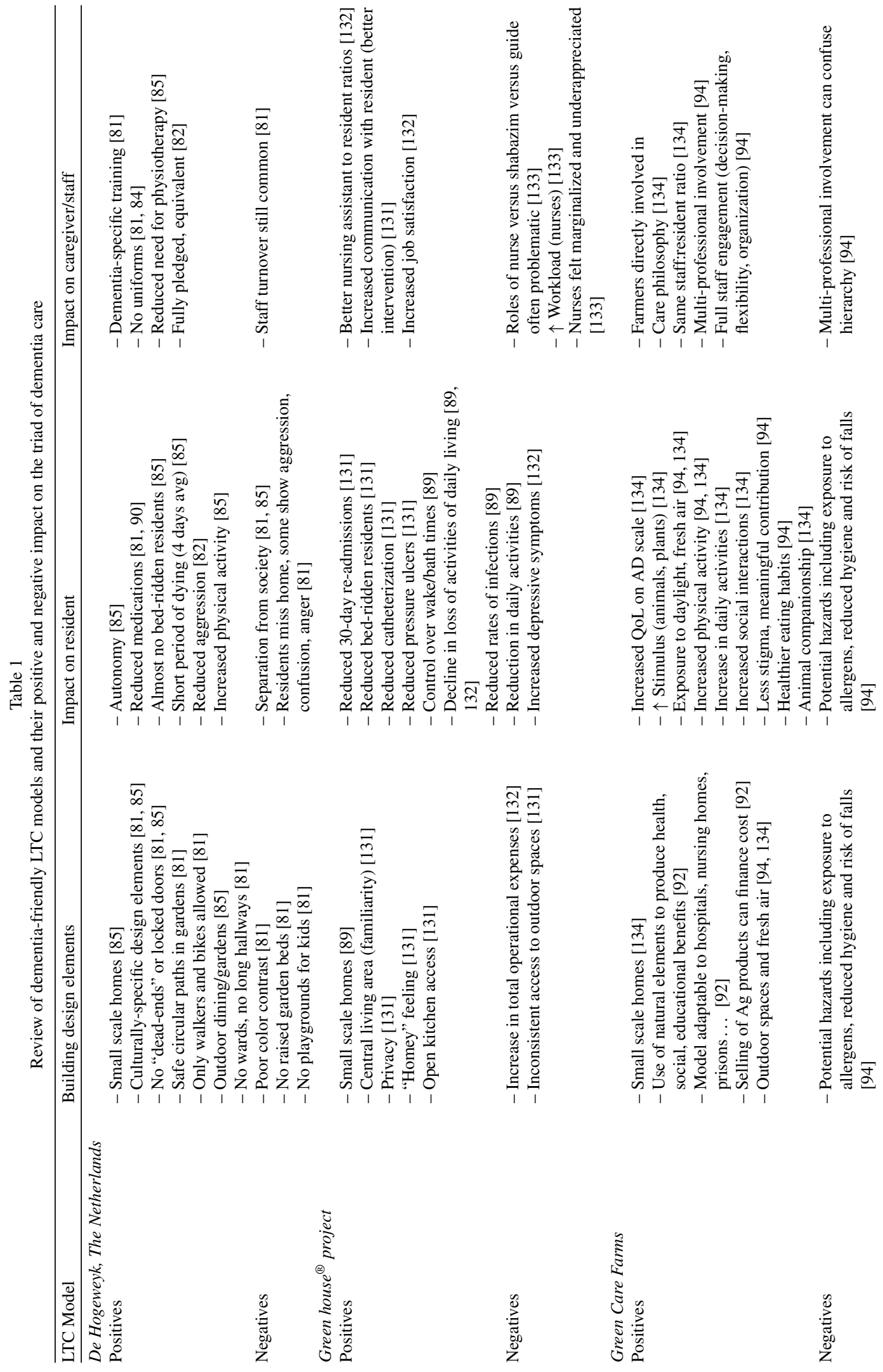



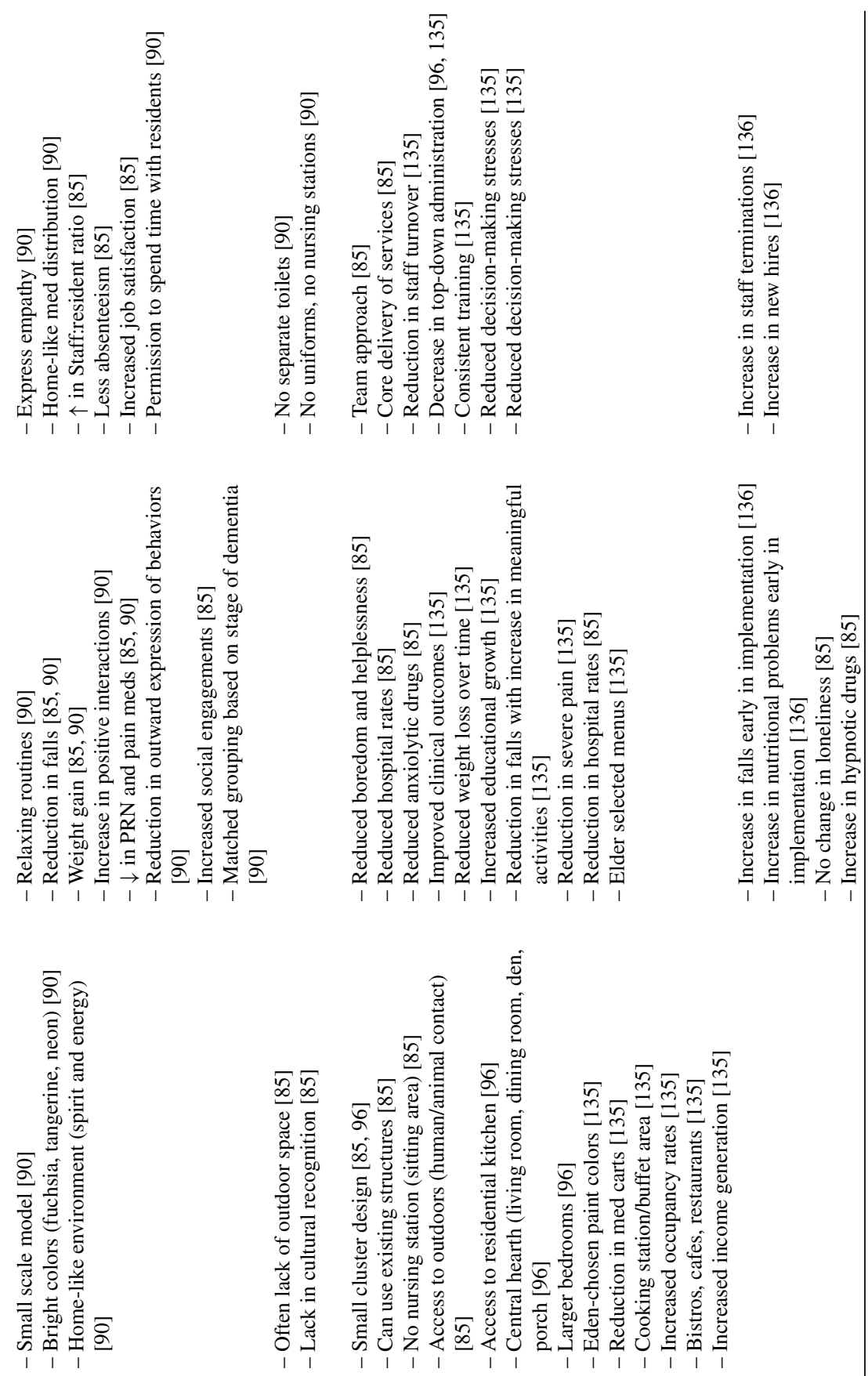

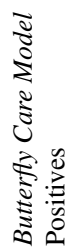

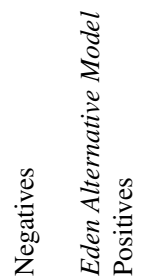

芯 

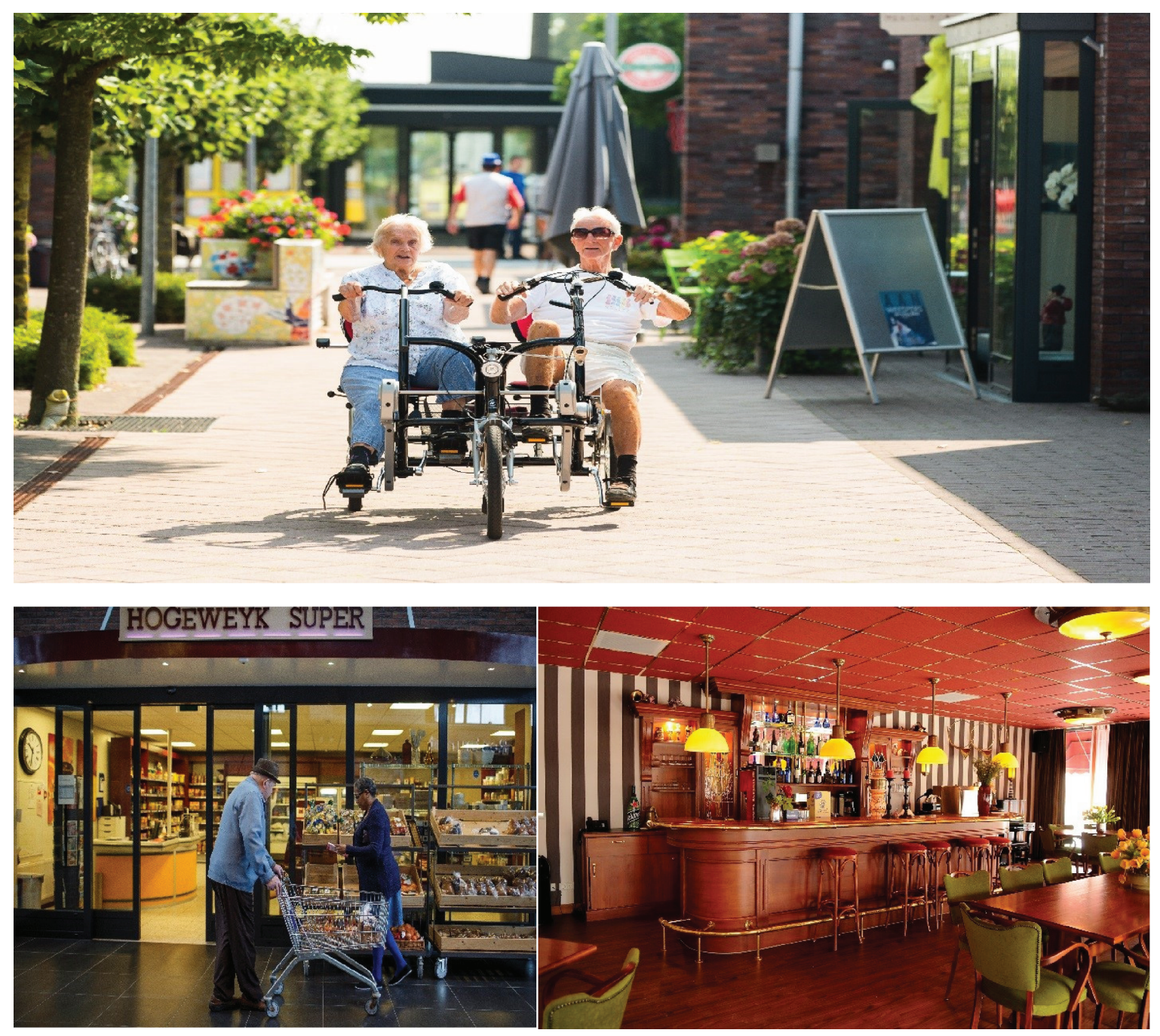

Fig. 1. A day in the life of the De Hogeweyk Dementia Village in Weesp, The Netherlands. Reprinted with permission from the Hogeweyk ${ }^{\circledR}$ Care Concept.

anxiety. The four most recent lifestyles assigned to the residents include Urban, Traditional, Cosmopolitan, and Formal [82, 84]. This model of care has won multiple awards for innovation and design and stands as a role model for other countries. There have been some ethical arguments against this model including the use of "deception" and the creation of a false reality, as well as stigma and separation of residents from the real world [85]. The "Dementia Village" concept has been replicated to some degree in Denmark (Bryghust-Svendborg Dementia Town; 2015), Switzerland (Weidlisbach; 2017), Ireland, Germany, France, New Zealand, Australia, and Canada (Comox, Langley, and Vancouver in British Columbia; Saskatoon in Saskatchewan) [85, 86]. In some "Dementia Villages", residents are not matched for cultural background, lifestyle, or shared interest, but they do follow the basic De Hogeweyk "Dementia Village" concept [85]. Although "Dementia Villages" have not yet been replicated in the U.S., a "retro" day village concept has emerged [87]. One example is Glenner Town Square in Chula Vista, California that mimics a Main Street, U.S. style of 1953-1961 and uses props such as fire hydrants, era furniture. and old movie houses to create a community atmosphere [87]. The company behind this concept (George G. Glenner Alzheimer's Family Centers) plan to construct 100 "retro" day villages within the next 20 years, including in Baltimore, Maryland and Louisville, Kentucky [87]. 

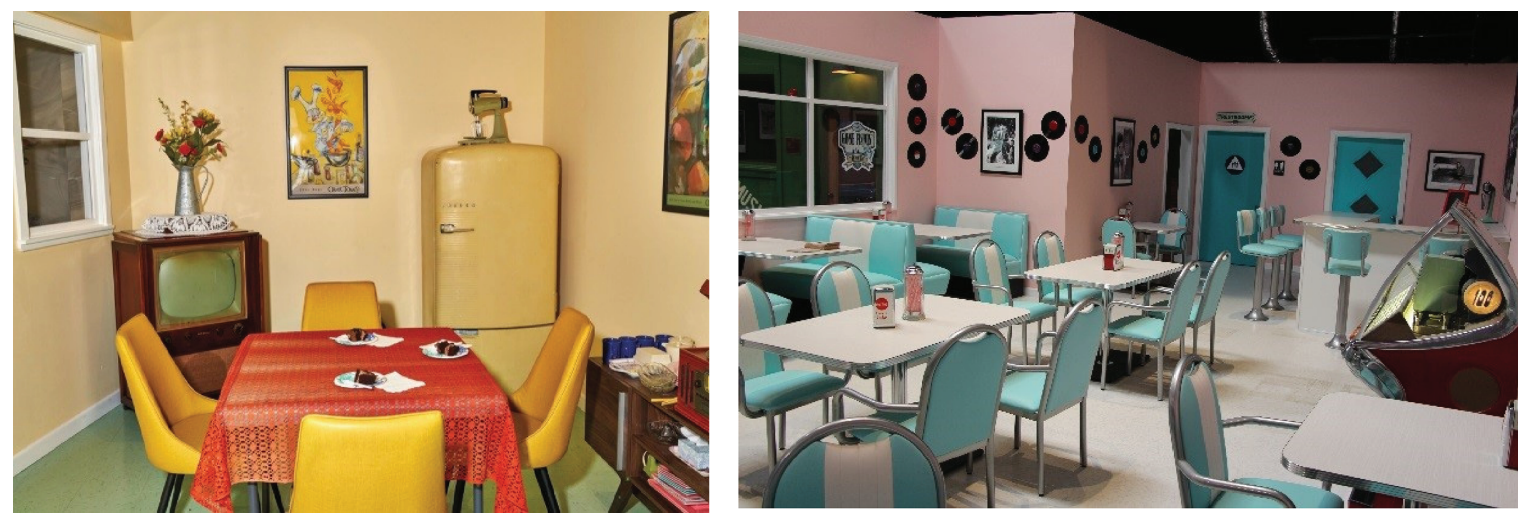

Fig. 2. Glenner Town Square: A typical dining room at home and Rosie's Diner. Reprinted with permission from the George G. Glenner Alzheimer's Family Centers, Inc ${ }^{\circledR}$.

\section{The Green House ${ }^{\circledR}$ Project (GHP), U.S.}

Initiated in the U.S. in 2003 by pediatrician Bill Thomas and The Robert Wood Johnson Foundation, the Green House ${ }^{\circledR}$ model is flexible and can accommodate dementia residents in a small-scale assisted living or nursing home model [88]. The GHP "Best Life" Dementia Care Model is a unique, holistic dementia care approach that helps those living with dementia to live rich and rewarding lives [88]. It is a standalone educational and training option for progressive-minded memory care, assisted living, and nursing home providers. The GHP organizational model is based on three core principles: real home, meaningful life, and empowered staff.

Small scale model. "Green" homes are generally small scale, self-contained, and self-sufficient, with residents called "elders" and nursing assistants called "Shahbazim". For the most part, each home has 10-12 "elders", each with a private room and attached bath, access to an open central kitchen, dining and living area (hearth), and access to outdoor space [89]. The "Shahbazim" are responsible for a range of personal, clinical, and home care activities including caregiver tasks, cooking, cleaning, laundry, ordering, and scheduling [89]. A "Guide", who coach and supervise them, supports these nursing assistants. A nurse is available $24 \mathrm{~h}$ a day. Often, residents have control over decision-making, including when to awake and go to bed, and when to bathe, which some staff find problematic [89]. One shortfall associated with many GHP homes was the lack of pre-scheduled daily activities, and lack of outings, which are difficult to accommodate with the staffing model available [89]. The capital costs to build Green House ${ }^{\circledR}$ facilities are higher than other models, but provide almost double the space per resident than a traditional nursing home [85].

Nursing home model. The first urban Green House $^{\circledR}$ skilled nursing facility in the country was The Leonard Florence Health Center in Boston, U.S. World recognized when it opened in 2010, it consists of ten "condo style" homes on six floors. Each "home" accommodates ten residents and features spacious private rooms with a bath, shower, and flat-screen TV, 24-hour café, European day spa, library/family room, chapel, and outdoor patio, dining area, open kitchen, and fireplace living room for each "home", and on-site therapy gym, complete with weights, bikes, and balance bars [39].

\section{The Butterfly Care Model, U.K.}

"The language of dementia isn't literal; the language of dementia is feeling". These are the words of Dr. David Sheard, who founded the first personcentered Butterfly Care Model in the U.K. in 1995 (Merevale House in Atherstone, UK) [90]. This model has spread throughout Ireland, Australia, and most recently Canada and the U.S. As of November 2018, more than 30 care homes have adopted this model, with 24 in the U.K., seven in Canada (Alberta and Ontario), three in Australia, and one in the U.S. (Stone Mountain, Georgia), with others planned in France, Denmark, Scotland, Japan, Norway, Italy, New Zealand, and Australia [85, 90, 91]. The home is split into a number of small living spaces (10-12 residents per space). The care home is filled with common household items (picture books, yarn, soft toys) in hopes of reminding residents of their old roles at work or home [91]. The walls are brightly colored to differentiate rooms and bring out 
the 'spirit' of people. Staff, who often wear street clothes instead of scrubs, are trained to express empathy, spend time with residents and change how they think and feel about dementia with a focus on the 'whole person' [90,91]. This model of care has shown clinical improvements in dementia patients including a reduction in the number of falls, reduced use of PRN (as needed) pain relief and medication, including anti-psychotic medication, reduction in outward expressions of behavior, an increase in positive interactions, fewer hospital admissions, and weight gain in residents [90, 91].

Green Care Farms ${ }^{\circledR}$, Somerset, New Jersey, U.S. (Green Care Farm Model)

The "Green Care" concept originated in The Netherlands in the 1990s and spread to Norway, Belgium, Finland, Germany, Italy, the U.K., Japan, and eventually the U.S. [92]. Green Care links aspects of traditional healthcare systems to agriculture (care farming), gardening (healing gardens), landscape or nature conservation (ecotherapy), animal keeping (Animal Assisted Interventions; AAI) and animal husbandry (care farming). It provides agricultural and care services to a diverse healthcare population, including PWD [93]. Generally, care farms offering adult day services serve people with mild to moderate dementia, whereas care farms providing 24-h nursing care provide services to people in the later stages of dementia [94]. Activities at the Green Care Farm include domestic chores (e.g., peeling potatoes, cooking, growing vegetables, collecting milk, collecting eggs, gardening, sweeping the yard) or involve animals (e.g., sowing, feeding cattle and other animals such as sheep, chickens, dogs, and cats) [93, 94]. The New Jersey, U.S. model includes a farm house (maximum of 15 residents) designed for the resident with cognitive impairment [95]. The singlestory structure, with a single entry/exit point, enables wayfinding, which reduces agitation. The farm features a veranda, raised beds, chicken coup, multiple activity area, barn, farm pets, and a greenhouse for gardening, and contains eco-friendly technologies such as solar power, rain water harvesting, and efficient HVAC system [95].

\section{Irene Baron Eden Centre, Winnipeg, Canada (The Eden Alternative Care Philosophy)}

The Eden Alternative (EA) care philosophy was developed in the 1990s by William H. Thomas (of the GHP principle). It was designed to combat the "three plagues" of LTC (boredom, loneliness, helplessness)
[96, 97]. It is based on 10 principles of care that focus on an elder-centered care model, contact with people, plants, and animals, spontaneity, meaningful activities, and reduction in top-down bureaucracy [96]. The Irene Baron Eden Centre in Winnipeg, Canada, built in 2009, is an example of a LTC model based on the EA principles of care [39]. Four buildings house twelve residents each, grouped around a hearth area of living room, dining room, den, and porch with a residential style kitchen in each household. The building is designed as residential occupancy (C occupancy) but still incorporates the safety elements of a personal care home, including wander guard protection, smoke control, and widened stairways. There is a dedicated house for lower functioning residents with advanced stages of dementia, and skilled nursing care is available 24/7 [39].

\section{DEMENTIA-FRIENDLY DESIGN ELEMENTS AND THEIR IMPACT ON PWD}

"Design can be inclusive, can be both function and aesthetic and can change people's lives for the better" [72].

Each care model we reviewed took specific design elements into account during the design process to improve the QoL and QoC for PWD and reduce stress in the resident and caregiver/staff. Poorly designed elements can reduce visual clarity, reduce contrast recognition, disrupt sleep, increase neuropsychiatric symptoms, increase confusion, increase the risk of falls, create unsafe way finding and elopement, increase the rate of decline in memory and cognition, and increase the rate of morbidity and mortality. These behaviors can lead to pharmacological interventions and restraint usage, and severely impact the ability of PWD to remain in isolation and fight off illness, disease, and infection (including COVID19) and other stresses. Properly designed elements can help reverse the negative impacts on PWD and may reduce the rates of morbidity and mortality. "Living Well with Dementia" involves the reduction or minimalization of the four 'A's' of dementia: apathy, anxiety, agitation, and aggression [98]. A person-centered holistic approach to dementia care combines the material environment, the social environment and pharmacological means [98]. One bonus of environmental interventions is that they are appropriate for any type and stage of dementia, unlike many pharmacological interventions [99]. Universal 
Design guidelines for dementia-friendly dwellings include eight elements: 1) participatory design; 2) familiar design; 3) personalization of design; 4) easy-to-interpret and calm environments; 5) safe and accessible outdoor spaces; 6) distinct spaces; 7) unobtrusive safety measures and technologies; and 8) good visual access [10]. The "Living Lab" concept of dementia design involves PWD at all stages of disease, along with professional teams of architects, landscape designers, technologists, museum and gallery curators, interior designers, product manufacturers, and clinical nursing and medical psychological staff [68]. The following design elements can apply to LTC, as well as the home and community.

\section{Lighting}

The average 75-year-old requires four times the light than their 25-year-old counterpart [100, 101]. As a person ages, their eyeballs thicken and become yellow, which filters out blue light, required to generate melatonin in the body [101]. Melatonin is a natural hormone secreted by the pineal gland in response to darkness and is controlled by the suprachiasmatic nucleus (SCN) located in the hypothalamus [102]. PWD may have abnormalities in this part of the brain, which lead to lower melatonin levels and disruption in the circadian rhythm (i.e., the body's natural clock) [103, 104]. This disruption can present itself as "sundowning" (SD), "sundown syndrome", or "nocturnal delirium" in which PWD exhibit worsening neuropsychiatric symptoms (anxiety, agitation, irritability, nighttime disturbances) in the late afternoon and evening, a phenomena not given a formal psychiatric diagnosis in the Diagnostic and Statistical Manual of Mental Disorders (DSM) and yet recognized in PWD for over 60 years [102-104]. Sundowning can affect 10-25\% of institutionalized PWD and $66 \%$ of community-dwelling PWD and may be caused in part by a lack of exposure to natural light during the day [100, 102-107]. Exposure to natural light is known to produce vitamin $\mathrm{D}$, increase productivity, protect vision, and improve sleep and mood [100]. Other eye problems in PWD include blurring and increased sensitivity to glare, inability to distinguish contrast (e.g., between floor and carpet) and a requirement for higher light levels [68]. Many LTC institutions have standard lighting levels without consideration to the color temperature [39]. It is believed that both light intensity (lux) and spectral wavelengths (k) are important to maintain circadian rhythms [39]. Early morning exposure to natural light for at least $2-3 \mathrm{~h}$ at 1000 lux minimum has been shown to improve sleep and reduce agitation in PWD $[100,105,106,108]$ and exposure to brighter artificial light in the blue wavelength has also proven to be therapeutic [102, 105]. Exposure to higher lighting levels using a bright light box (2,500 to 10,000 lux) is associated with improved circadian rhythm quality and mood, increased consolidation of night-time sleep, increased daytime wakefulness, alertness, and MiniMental State Exam scores, and decreased agitation and disruptive behavior [42]. Design elements that improve lighting and reduce confusing shadows and glare include installation of anti-glare, non-reflective glass throughout the building including bedrooms, bathrooms, and kitchens, brighter ambient light in the blue spectrum in common areas, access to outdoor spaces, yellow amber night lights to aid in night care, removal of bright lights over beds, strip lighting around doors and on floors leading to the bathroom, window coverings to reduce glare and bright moonlight at night, use of Light Emitting Diodes (LED), skylights with diffusers to reduce glare, and avoidance of shiny floors and surfaces $[10,39,101$, 109-112].

\section{Color and contrast}

PWD are prone to visual impairment, which may include a reduction in contrast perception (ability to differentiate subtle changes in environment, such as carpets, floors, walls, and steps), a reduction in perceived saturation or vividness of colors (e.g., reds become pink), and a progressive reduction in the ability to perceive the blue end of the spectrum [68]. For some PWD, things may be blurred, moving, less three-dimensional or just unrecognizable [113]. The selective use of colors and tonal contrast can help differentiate objects, define borders, assist wayfinding, prevent trips and falls, reduce anxiety, and encourage independence $[39,68,113,114]$. The blue end of the spectrum contains the "cool" colors: Blue can create a sense of calm and make a room seem larger in size and cooler in temperature; green is associated with nature, can reduce central nervous activity, calm and relax someone, and can also makes a room seem larger and cooler $[114,115]$. The red end of the spectrum contains the "warm" colors: Red and orange increase brain activity, can stimulate the production of adrenalin, and make a room feel smaller and warmer [114, 115]. Although PWD can show a marked decrease in color naming ability, they prefer blue, red, and green in that order when given color 


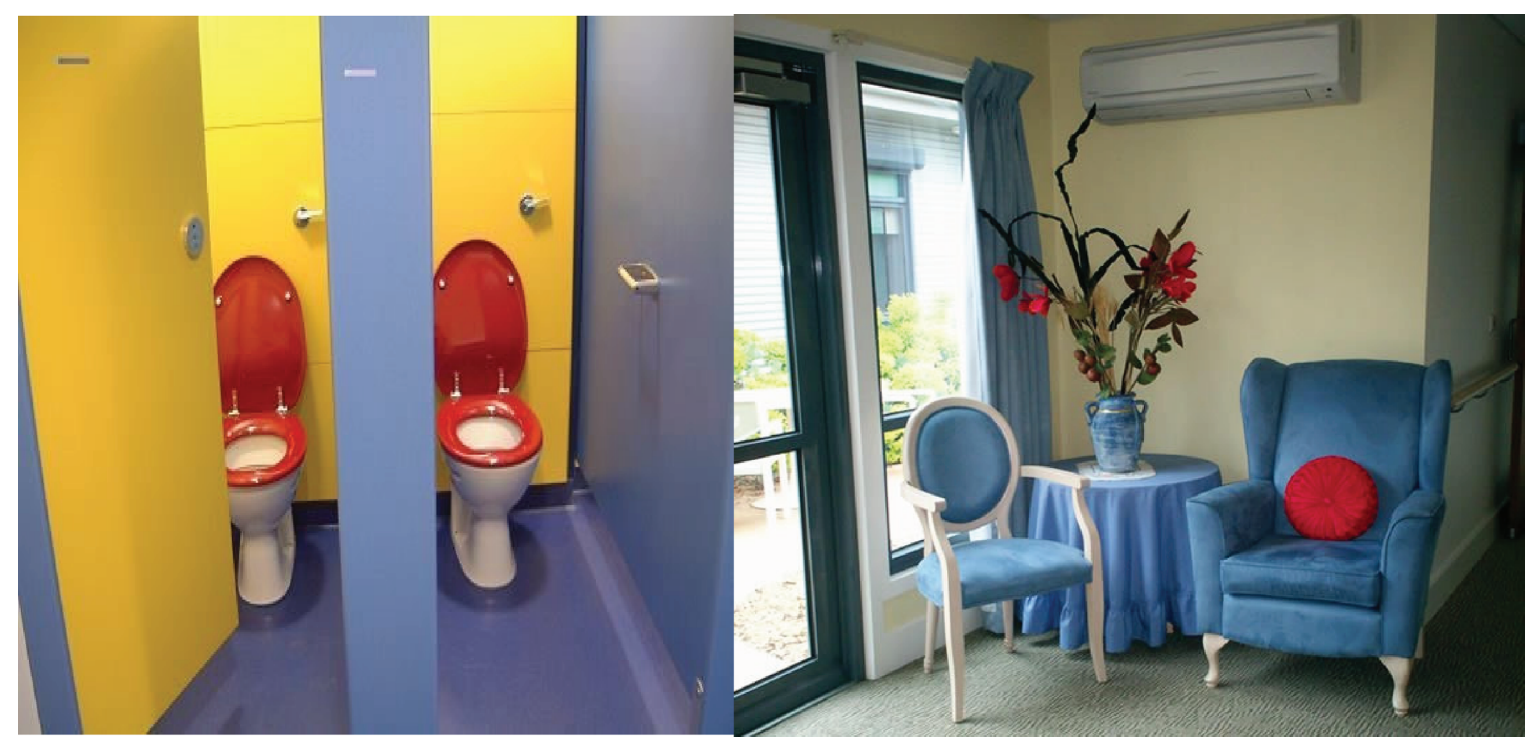

Fig. 3. An example of color contrast for a toilet seat and the use of natural lighting and color contrast to define a space. Reprinted from Google Free Images.

cues [114-116]. The lightness of the color (tint and shade) can impact the ability to recognize a color [114]. Design elements that can improve color contrast and wayfinding and reduce falls and confusion include painting of doors, light switches and wall mounted fittings a different color from the background, avoidance of very dark or pastel colors, use of non-glossy matte finishes, simple solid floor patterns and colors with no black lines, swirls or circles which could be confused for holes or water, and a clear delineation between objects (e.g., toilets, furniture, grabrails, dining plates, shelves, cupboards) and their surroundings [10, 39, 68, 110]. Colors with a Light Reflective Value (LRV) of $>65 \%$ should be used on all surfaces. LRV measures the percentage of light a paint color reflects, and high LRV paint will "bounce" daylight deeper into spaces improving orientation and visual acuity for residents [39].

\section{Wayfinding and orientation}

Spatial disorientation is one of the prime reasons for institutionalization of PWD [117]. Internal representation of the environment in one's mind are called "cognitive maps", which are also referred to as the mind's eye (precuneus) [117]. As dementia progresses, the cognitive map deforms and breaks apart, causing deteriorating orientation. Unsafe wayfinding can lead to falls, which leads to poor health outcomes, including the ability to recover from infections such as COVID-19. Wayfinding (orientation) involves the following components: knowing where you are, knowing where you are going (destination), knowing how to get somewhere (mental map), recognizing when you've arrived and knowing how to get back $[39,118]$. Barrett et al. (2019) states that wayfinding requires: 1) a manageable cognitive load; 2) clear sequencing; and 3) appropriate level of stimulation [98]. Most institutions lack the visual cues required to accommodate safe wayfinding, with long doubleloaded corridors with equally spaced doors, a lack of distinctiveness of different areas, and poor environmental cues [119]. Orientation involves both building design (size of scale, spatial anchor points, places with different and legible function and meaning) and environmental design (signage, labels, art, pictures, use of color, personal items on doors) [118]. PWD use allocentric navigation in their environments (i.e., use landmarks and external cues for orientation, rather than rely on self). Architectural design details that can improve wayfinding include use of small scale "cluster" design (10-12 residents per "home"), spatial layout that provides a continuous circuitous route (L-shaped or circular routes around a central courtyard, rather than long dead-end hallways), visual cues at each change of direction, elimination of corridors where possible, a centralized kitchen/dining/living area that serves as a central orientation point, use of murals to hide exit doors from the inside, access to bathrooms from the bed, access to outdoor spaces, 


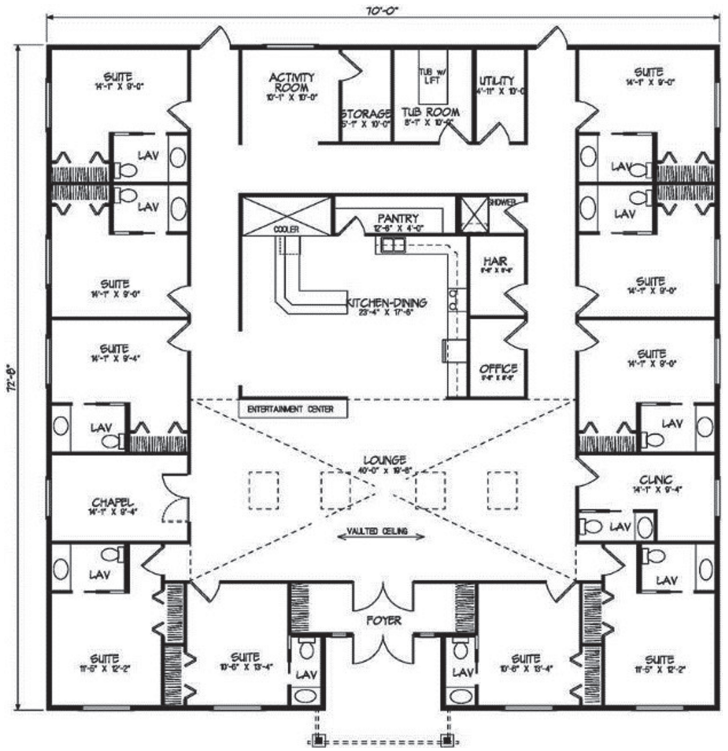

Fig. 4. A floor plan with central hearth area to aid in wayfinding. Reprinted from Google Free Images.

and use of surface materials, signage, labels, pictures, color, art, lighting, memory boxes on resident doors, and other "salient" (bright, distinctive) cues to aid in orientation within a space $[39,42,43,68,93,98,110$, 111, 118-122].

\section{Outdoor spaces}

Studies have shown that access to gardens and outdoor space can produce many stress-reducing, restorative benefits in PWD including improved mental health, improved QoL and mood, reduced agitation and aggression, reduction in blood pressure and muscle tension, reduction in falls, improved sleep efficiency and sleep duration (circadian rhythm), socialization, improvement in cognitive scores, and reduced use of behavioral medication [39, 42, 123]. In fact, a green view and access to external garden space can reduce the symptoms of dementia by $50 \%$ [68]. Benefits may be the result of two mechanisms: reminiscence and sensory stimulation [123]. For PWD in LTC, having unhindered access to an outdoor garden that loops naturally back to the main building allows PWD to wander independently without getting lost [107]. Physical activity, exposure to fresh air and sunlight, contact with plants and animals, and exposure to seasonal change that comes with outdoor spaces are therapeutic to PWD, can provide information about the time of day and aid in wayfinding [10]. Architectural design elements that aid in wayfinding and provide safe, calm outdoor environments include unhindered, unlocked, and safe access from inside (with signage to direct residents to the garden), non-slip, non-shiny wide level walkways with gentle grades, a circuitous loop design, elevated fences that prevent climbing, hidden gates and locks on fences to prevent elopement, textures and forms of materials that provide a tactile experience, and continuity of surfaces. Other elements include aromatic non-toxic seasonally interesting plants, low plantings near windows that do not hinder inside views of the space, potted plants placed near seating areas, safe water features to encourage calm, handrails, shade trees to sit under, furniture placed along paths and near beds and trees, features to attract birds or wildlife, raised beds to allow for gardening activities, adequate lighting for evening visits, and open spaces for picnics, barbeques, and activities [10, 39, $68,124,125]$.

\section{Other dementia-friendly design elements}

Other design elements that can improve QoL for LTC residents and help reduce stress and provide a sense of independence, include reduction in loud noise (e.g., alarms and paging systems) to prevent over-stimulation but addition of pleasing noises that reduce boredom (e.g., background music), temperature controls and ventilation systems that reduce drafts and cold spots in a LTC facility and prevent the spread of respiratory viruses and other contaminants, a reduction in overall clutter, "home-like" décor including art, bedspreads, furniture, and personal items that provide familiar comfort, and "homelike" dining areas with non-institutionalized seating arrangements. Other friendly elements include private person-centered bedroom, shower and bath design, spaces for recreational activity (e.g., music therapy, arts and crafts, games, reading, exercise), improved sightlines, reduction of barriers to allow purposeful wandering, non-institutionalized ambiance and design elements, and the use of SMART technologies $[39,42,68,98,102,111,113$, 126].

\section{DISCUSSION}

"Making lives meaningful in old age is new. It therefore requires more imagination and invention than making them merely safe does" [39].

The United Nations (UN) Convention on the Rights of Persons with Disabilities (including 


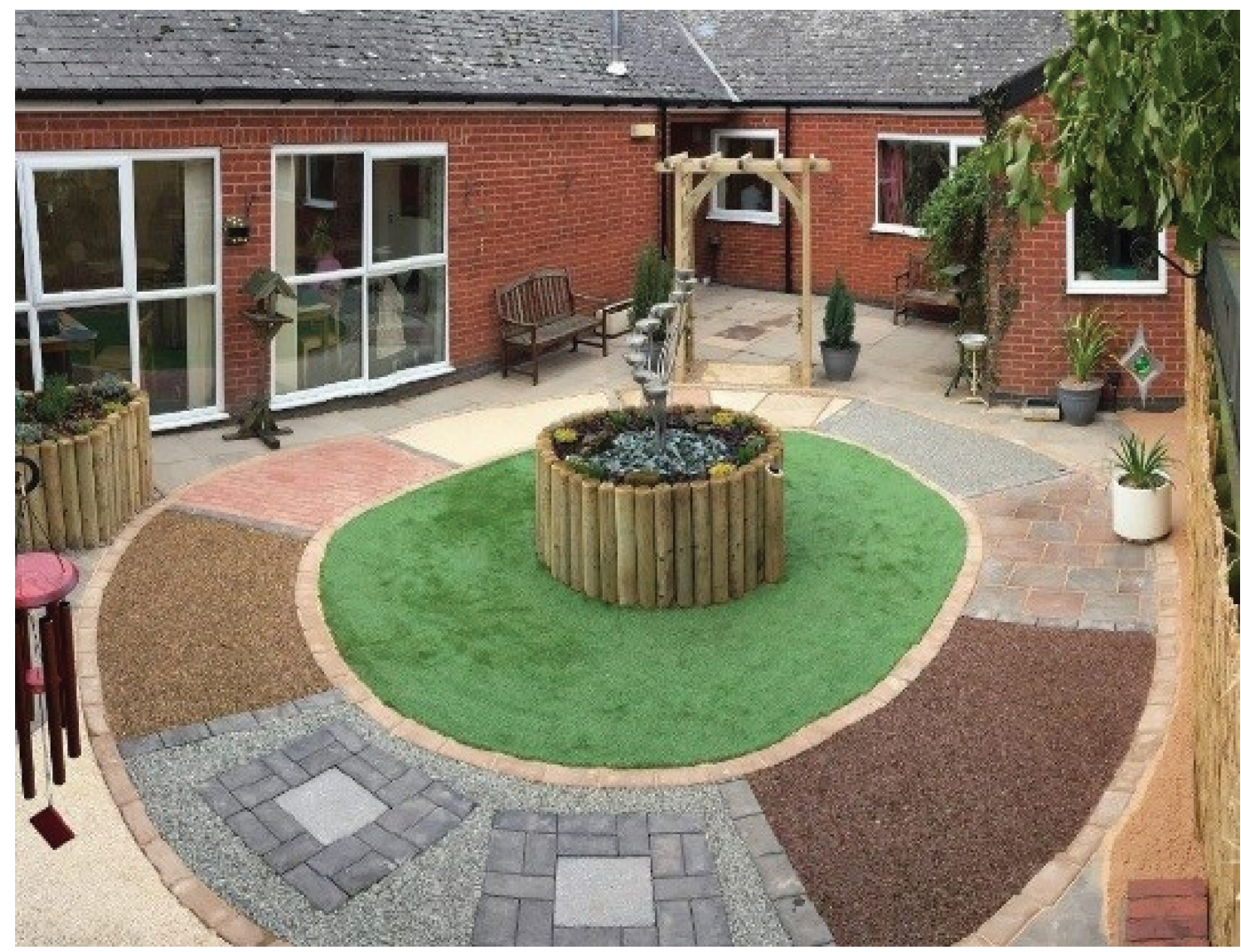

Fig. 5. A looped pathway design in an outdoor garden. Reprinted from Google Free Images.

dementia) states that persons living with dementia have the right to the full range of healthcare, including diagnosis, treatment, rehabilitation, health promotion, disease prevention, risk reduction, social support, and palliative care (United Nations, Committee on the Rights of Persons with Disabilities, 2017) [34]. If we look at this statement as written, we can argue that placement of PWD into institutional LTC facilities with 24-h staffing and access to food, medication, and shelter covers the basic needs under the UN Convention. COVID-19, however, laid bare the inadequacies of many care models the world over, especially as it relates to disease prevention, risk reduction, and social support.

Old, institutionalized buildings with inadequate infection control design, inadequate ventilation that could spread germs throughout a building, dense populations, shared bedrooms and bathrooms, large communal gathering rooms, lack of access to the outdoors, and narrow hallways and crowded nursing stations placed PWD at a high risk of contracting COVID-19 and spreading it throughout the facility. Add to this poor staffing levels, a poor staffing mix, and poor staff training in dementia-specific care and infection control practices, and COVID-19 proved too much for many LTC facilities to handle. Staff were already often poorly paid, part-time or casual, had no benefits such as sick leave, and often worked in multiple facilities, which along with poor contingency planning for infectious disease outbreaks, exacerbated an already stressful work environment and placed residents and staff at risk of getting infected.

Older people and their caregivers suffer disproportionately in times of disaster [78]. When COVID-19 struck, governments the world over poured most of their COVID-19 resources into hospitals, in terms of adequate PPE, equipment, and staff, leaving LTC facilities without the basic requirements to prevent the rapid spread of the virus. New York City was criticized early in the pandemic for failing to support Nursing Homes in their bid to acquire PPE and other supplies, with the state Governor saying "It's not our job to ensure that the Nursing Homes had adequate PPE" [127]. Also, hospitals often refused to accept LTC patients or quickly shipped positive patients 
back to the Nursing Home, and PWD were kept in their facilities, either isolated alone or with other infected residents, shut out from the outside world with no access to their loved ones, which increased their rates of depression, agitation, and loneliness and put them at even greater risk of morbidity and mortality from COVID-19. PWD are often vulnerable to infections due to frailty, poor lung health, multiple co-morbidities, and an inability to express their symptoms such as pain to caregivers. To complicate matters, COVID-19 often presented in PWD as asymptomatic carriage, so many PWD died with COVID-19 but were never tested, thus the death rates were most likely higher than officially presented in the media. In New York City, COVID-19 patients that died in hospital, even if infected in their facility, were excluded from the death count, which also artificially lowered the death count of PWD and other residents in LTC [128, 129].

Although COVID-19 was unprecedented in scope and severity, the peoples, societies, and organizations who have written about deplorable conditions in LTC for decades and begged their governments for increased funding, have predicted a "tipping point" was inevitable, and many individuals such as Bill Gates, Barack Obama, and George W. Bush predicted that a global pandemic could be that "tipping point". The U.S. ranked first in the world for pandemic preparedness (83.7 on the Global Health Security Index) with the U.K. second at 77.9 [130]; however, both countries, like most of the world, were woefully unprepared when the pandemic struck. Disasters will strike again (pandemics, antibiotic-resistant infections, global climate change), and when you combine high-risk frail residents, poorly trained and paid caregivers/staff, and old, poorly designed, institutionalized, and overcrowded buildings, along with poor disaster contingency planning, poor outcomes will follow.

During COVID-19, some of the dementia-friendly initiates reviewed in this paper could have prevented the high death rates among PWD around the world, if for no other reason than they would have kept those with dementia away from the crowded, poorly managed and poorly staffed institutions, and reduced the density which led to overwhelming outbreaks. Simple design element changes and small scale "cluster" design could have aided in isolation of COVID-19 residents in single bedrooms, reduced stress, agitation, and aggression, improved sleep quality, reduced the risk of falls, reduced restraint and medication usage, improved the ability of the caregiver/staff to supervise them, and kept family members involved directly with their care, without requirements for extensive PPE or hospitalization. Happier, healthier, and less stressed PWD along with well-paid, welltrained, satisfied full-time caregivers, and buildings designed specific to dementia care could have combined to benefit those same governments that have failed to adequately fund LTC in the first place. The original question asked in the Introduction was: What went so wrong during this pandemic and what can we do to change the future of dementia care and housing so it never happens again? Governments now probably know what needs to be done; increased funding for caregivers, including an increase in the numbers of full-time staff with benefits, an increase in standardized training requirements for all LTC staff, better disaster contingency planning, upgraded building codes and national inspection guidelines that punish those institutions that do not comply, and an increase in initiatives such as dementia-friendly homes and communities, which keep PWD at home longer, or small-scale LTC facilities designed to accommodate and protect this unique population. These initiatives cost money up front, which may be a barrier for those looking to fund future LTC models and requires a "thinking outside the box" philosophy, but many communities around the world have started the ball rolling and can be an inspiration and a source for new ideas and new design.

\section{ACKNOWLEDGMENTS}

The authors would like to thank Jannette Spiering, Senior Managing Advisor/Founder of De Hogeweyk ${ }^{\circledR}$, and Lisa D. Tyburski, Chief Marketing Officer for the George G. Glenner Alzheimer's Family Centers, Inc ${ }^{\circledR}$ for their contributions of knowledge and pictures for this publication. The research was funded by Canadian Institutes of Health Research (CIHR), grant No. PJT-162144, and the St. Boniface Hospital Research Foundation, grant Nos. 1406-3216 and 1410-3216. This work was also supported by Research Manitoba (to BCA), and the Alzheimer's Society of Manitoba, thru the Honorable Douglas and Patricia Everett, and Royal Canadian Properties Limited Endowment Fund to Dr. Albensi. BCA holds the Manitoba Dementia Chair and is a Research Affiliate of the Centre on Aging at the University of Manitoba.

Authors' disclosures available online (https:// www.j-alz.com/manuscript-disclosures/21-0017r1). 


\section{REFERENCES}

[1] Azarpazhooh MR, Amiri A, Morovatdar N, Steinwender S, Rezaei Ardani A, Yassi N, Biller J, Stranges S, Tokazebani Belasi M, Neya SK, Khorram B, Sheikh Andalibi MS, Arsang-Jang S, Mokhber N, Di Napoli M (2020) Correlations between COVID-19 and burden of dementia: An ecological study and review of literature. J Neurol Sci 416, 117013.

[2] Estabrooks CA, Straus S, Flood CM, Keefe J, Armstrong P, Donner G, Boscart V, Ducharme F, Silvius J, Wolfson M (2020) Restoring Trust Document: Covid-19 and The Future of Long-Term Care. The Royal Society of Canada.

[3] Hado E, Friss Feinberg L (2020) Amid the COVID-19 pandemic, meaningful communication between family caregivers and residents of long-term care facilities is imperative. J Aging Soc Policy 32, 410-415.

[4] Weiss J, Tumosa N, Perweiler E, Bailey D, Blackwell E, Forceia MA, Miles T, Tebb S, Trudeau S, Worstell M (2017) Workforce Gaps in Dementia Education and Training: Stakeholder Group Paper. Research Summit on Dementia Care.

[5] Song Y, Anderson RA, Corazzini KN, Wu B (2014) Staff characteristics and care in Chinese nursing homes: A systematic literature review. Int J Nurs Sci 1, 423-436.

[6] American Psychiatric Association (2000) Diagnostic and statistical manual of mental disorders: DSM-IV-TR. American Psychiatric Association, Washington, DC.

[7] The World Health Organization (WHO) definition of Dementia, https://www.who.int/news-room/fact-sheets/ detail/dementia, Accessed September 21, 2020.

[8] The Government of Canada: A Dementia Strategy for Canada: Together We Aspire, www.canada.ca/en/publichealth/services/diseases/dementia.html, 2019.

[9] de Rooij AH, Luijkx KG, Declercq AG, Schols JM (2011) Quality of life of residents with dementia in long-term care settings in the Netherlands and Belgium: Design of a longitudinal comparative study in traditional nursing homes and small-scale living facilities. BMC Geriatr 11, 1-9.

[10] Grey T, Pierce M, Cahill S, Dyer M. Universal Design Guidelines: Dementia Friendly Dwellings for People with Dementia, Their Families and Carers. Trinity College Dublin. http://www.universaldesign.ie

[11] Cotter VT (2007) The burden of dementia. Am J Manag Care 13, S193-S197.

[12] Cadieux MA, Garcia LJ, Patrick J (2013) Needs of people with dementia in long-term care: A systematic review. Am J Alzheimers Dis Other Demen 28, 723-733.

[13] (2020) American Geriatrics Society: Policy Brief: COVID-19 and nursing homes. J Am Geriatr Soc 68, 908-911.

[14] Andrew M, Searle SD, McElhaney JE, McNeil SA, Clarke B, Rockwood K, Kelvin DJ (2020) COVID-19, frailty and long-term care: Implications for policy and practice. $J$ Infect Dev Ctries 14, 428-432.

[15] Government of Canada: About Coronovirus Disease (COVID-19), https://www.canada.ca/en/public-health/ services/publications/diseases-conditions/aboutcoronavirus-disease-covid-19.html

[16] Public Health Agency of Canada - Infection Prevention and Control: Coronavirus (COVID-19) SARS CoV-2, info@ipac-canada.org,

[17] World Health Organization Regional Office for Europe: WHO announces COVID-19 outbreak a pandemic, https:// www.euro.who.int/en/health-topics/health-emergencies/ coronavirus-covid-19/news/news/2020/3/who-announces -covid-19-outbreak-a-pandemic, Accessed March 12, 2020.

[18] Brown EE, Kumar S, Rajji TK, Pollock BG, Mulsant BH (2020) Anticipating and mitigating the impact of the COVID-19 pandemic on Alzheimer's disease and related dementias. Am J Geriatr Psychiatry 28, 712-721.

[19] Government of Canada: COVID-19 signs, symptoms and severity of disease: A clinican guide, https://www. canada.ca/en/public-health/services/diseases/2019novel-coronavirus-infection/guidance-documents/signssymptoms-severity.html

[20] Hartford Health Care: Can an HVAC Duct spread COVID19 in Offices, Stores and Schools? https://hartfordhealth care.org/about-us/news-press/news-detail?articleid= 27158\&publicId=395, Accessed July 13, 2020.

[21] Shih RA, Concannon TW, Liu JL, Friedman EM. Rand Health Policy: Improving Dementia Long Term Care: A Policy Blueprint, https://www.ncbi.nlm.nih.gov/pmc/ articles/PMC5051994/?report=reader, Accessed June 1, 2014.

[22] Hwang JM, Kim JH, Park JS, Chang MC, Park D (2020) Neurological diseases as mortality predictive factors for patients with COVID-19: A retrospective cohort study. Neurol Sci 41, 2317-2324.

[23] Donnelly NA, Hickey A, Burns A, Murphy P, Doyle F (2015) Systematic review and meta-analysis of the impact of carer stress on subsequent institutionalisation of community-dwelling older people. PLoS One 10, 1-19.

[24] McMaster Optimal Ageing Portal (McMaster University): Does Caregiver Stress Affect the Move to Long Term Care? https://www.mcmasteroptimalaging.org/blog/det ail/blog/2016/09/07/does-caregiver-stress-affect-themove-to-long-term-care, Accessed September 7, 2016.

[25] Buhr GT, Kuchibhatia M, Clipp EC (2006) Caregivers' reasons for nursing home placement: Clues for improving discussions with families prior to the transition. Gerontologist 46, 52-61.

[26] Schultz R, Belle SH, Czaja SJ, McGinnis KA, Stevens A, Zhang S (2004) Long-term care placement of dementia patients and caregiver health and well-being. JAMA 292, 961-967.

[27] Alzheimer's Disease International (2019) World Alzheimer Report 2019: Attitudes to Dementia. Alzheimer's Disease International, London.

[28] Swaffer K (2014) Dementia: Stigma, language, and dementia-friendly. Dementia (London) 13, 709-716.

[29] Herrmann LK, Welter E, Leverenz J, Lerner AJ, Udelson N, Kanetsky C, Sajatovic M (2018) A systematic review of dementia-related stigma research: Can we move the stigma dial? Am J Geriatr Psychiatry 26, 316-331.

[30] Jason L. Powell, Chen S, International Perspectives on Aging. Springer International Publishing (Series 19). http://www.springer.com/series/8818, https://doi.org/10. 1007/978-3-319-73820-8.

[31] Cameron EJ, Bowles SK, Marshall EG, Andrew MK (2018) Falls and long-term care: A report from the care by design observational cohort study. BMC Fam Pract 19, 73 .

[32] CIHI, Dementia and falls: Lower Income Seniors with dementia more likely to be admitted to hospital for falls, https://www.cihi.ca/en/dementia-in-canada/spotlight-ondementia-issues/dementia-and-falls,

[33] Ye L, Richards KC (2018) Sleep and long-term care. Sleep Med Clin 13, 117-125. 
[34] Improving the quality of life and care of persons living with dementia and their caregivers. Canadian Academy of Health Sciences (CAHS), Ottawa, Canada., www.cahsacss.ca

[35] Gilster SD, Boltz M, Dalessandro JL (2018) Long-term care workforce issues: Practice principles for quality dementia care. Gerontologist 58, S103-S113.

[36] Spisova S, Baeten R, Coster S, Ghailini D, Pena-Casas R, Vanhercke B, Challenges in Long-Term Care in Europe: A study of national policies 2018. European Social Policy Network (ESPN). Brussels European Commission, http://ec.europa.eusocialmain.jsp?catId=1135\&langId=en, August 2018.

[37] Garrod L, Fossey J, Henshall C, Williamson S, Coates A, Green H (2019) Evaluating dementia training for healthcare staff. J Mental Health Train Educ Pract 14, 277-288.

[38] Mjorud M, Engedal K, Rosvik J, Kirkevold M (2017) Living with dementia in a nursing home, as described by persons with dementia: A phenomenological hermeneutic study. BMC Health Serv Res 17, 1-9.

[39] Wrublowsky R. Design Guide for Long Term Care Homes. MMP Architects, Accessed January 2018.

[40] Pedersen K, Mancini M, Wolfe-Wylie W (2020) Ont. Nursing Homes have had 22 years to do safety upgrades. COVID-19 reveals deadly cost of delay. Hard hit homes still operating at 1972 structural safety standard - and most are owned by for-profit companies., https://www.cbc.ca/ news/health/covid-19-coronavirus-long-term-carehomes-ontario-1.5604009

[41] Stall NM, Jones A, Brown KA, Rochon PA, Costa AP (2020) For-profit long-term care homes and the risk of COVID-19 outbreaks and resident deaths. CMAJ 192, E946-E955.

[42] Chaudhury H, Cooke HA, Cowie H, Razaghi L (2018) The influence of the physical environment on residents with dementia in long-term care settings: A review of the empirical literature. Gerontologist 58, e325-e337.

[43] Hague M, Designing for dementia: Long-term memory care, from the ground up., https://www.theglobe andmail.com/life/home-and-design/article-designing-fordementia-long-term-memory-care-from-the-ground-up/, Accessed August 11, 2019.

[44] Sepulveda ER, Stall NM (2020) A comparison of COVID19 mortality rates among long-term care residents in 12 OECD countries. J Am Med Dir Assoc 21, 1570-1572 e1571.

[45] Thompson DC, Barbu MG, Beiu C, Popa LG, Mihai MM, Berteanu M, Popescu MN (2020) The impact of COVID19 pandemic on long-term care facilities worldwide: An overview on international issues. Biomed Res Int 2020 , 8870249 .

[46] Bianchetti A, Rozzini R, Guerini F, Boffelli S, Ranieri P, Minelli G, Bianchetti L, Trabucchi M (2020) Clinical presentation of COVID19 in dementia patients. J Nutr Health Aging 24, 560-562.

[47] Mok VCT, Pendlebury S, Wong A, Alladi S, Au L, Bath PM, Biessels GJ, Chen C, Cordonnier C, Dichgans M, Dominguez J, Gorelick PB, Kim S, Kwok T, Greenberg SM, Jia J, Kalaria R, Kivipelto M, Naegandran K, Lam LCW, Lam BYK, Lee ATC, Markus HS, O'Brien J, Pai MC, Pantoni L, Sachdev P, Skoog I, Smith EE, Srikanth V, Suh GH, Wardlaw J, Ko H, Black SE, Scheltens P (2020) Tackling challenges in care of Alzheimer's disease and other dementias amid the COVID-19 pandemic, now and in the future. Alzheimers Dement 16, 1571-1581.
[48] Manabe T, Fujikura Y, Mizukami K, Akatsu H, Kudo K (2019) Pneumonia-associated death in patients with dementia: A systematic review and meta-analysis. PLoS One 14, 1-14.

[49] Gordon AL, Goodman C, Achterberg W, Barker RO, Burns E, Hanratty B, Martin FC, Meyer J, O'Neill D, Schols J, Spilsbury K (2020) Commentary: COVID in care homes-challenges and dilemmas in healthcare delivery. Age Ageing 49, 701-705.

[50] Chu CH, Donato-Woodger S, Dainton CJ (2020) Competing crises: COVID-19 countermeasures and social isolation among older adults in long-term care. $J A d v$ Nurs 76, 2456-2459.

[51] Simard J, Volicer L (2020) Loneliness and isolation in long-term care and the COVID-19 pandemic. J Am Med Dir Assoc 21, 966-967.

[52] Aronson L, For Older People, Despair, as Well as Covid-19 Is Costing Lives, New York Times, https://www.nytimes. com/2020/06/08/opinion/coronavirus-elderly-suicide. html, Accessed June 8, 2020.

[53] Jancin B, COVID-19: Psychiatrists assess geriatric harm from social distancing, MDEdge Neurology Website, https://www.mdedge.com/neurology/article/222771/ coronavirus-updates/covid-19-psychiatrists-assessgeriatric-harm-social, Accessed May 27, 2020.

[54] Fallon A, Dukelow T, Kennelly SP, O'Neill D (2020) COVID-19 in nursing homes. QJM 113, 391-392.

[55] Beland D, Marier P (2020) COVID-19 and long-term care policy for older people in Canada. J Aging Soc Policy 32, 358-364.

[56] Staffing and Care Standards for Long-Term Care Homes: Submission to the Ministry of Health and Long-Term Care. Registered Nurses' Association of Canada. http://www. rnao.org, December 2007,

[57] Pandemic Experience in the Long-Term Care Sector: How Does Canada Compare with Other Countries - Data Tables. Canadian Institute for Health Information (CIHR), Ottawa, Canada., https://www.cihi.ca/en

[58] Lynch RM, Goring R (2020) Practical steps to improve air flow in long-term care resident rooms to reduce COVID-19 infection risk. $J$ Am Med Dir Assoc 21, 893-894.

[59] Trabucchi M, DeLeo D (2020) Nursing homes or besieged castles: COVID-19 in northern Italy. Lancet Psychiatry 7, 387-388.

[60] McKenna T, Australia's COVID-19 successes shine a light on Canada's troubled long-term care sector: More than 6000 Canadians have died in long-term care homes from Covid-19 compared to 29 in Australia. CBC News, https://www.cbc.ca/news/world/australia-covid-19long-term-care-1.5591912, Accessed June 13, 2020.

[61] Nyashanu M, Pfende F, Ekpenyong M (2020) Exploring the challenges faced by frontline workers in health and social care amid the COVID-19 pandemic: Experiences of frontline workers in the English Midlands region, UK. $J$ Interprof Care 34, 655-661.

[62] Houghton C, Meskell P, Delaney H, Smalle M, Glenton C, Booth A, Chan XHS, Devane D, Biesty LM (2020) Barriers and facilitators to healthcare workers' adherence with infection prevention and control (IPC) guidelines for respiratory infectious diseases: A rapid qualitative evidence synthesis. Cochrane Database Syst Rev 4, 1-69.

[63] Villa S, Lombardi A, Mangioni D, Bozzi G, Bandera A, Gori A, Raviglione MC (2020) The COVID-19 pandemic preparedness... or lack thereof: From China to Italy. Glob Health Med 2, 73-77. 
[64] Kim G, Wang M, Pan H, G HD, Roxby AC, Neukirch J, Lei D, Hawken-Dennis E, Simpson L, Ong TD (2020) A health system response to COVID-19 in long-term care and post-acute care: A three-phase approach. J Am Geriatr Soc 68, 1155-1161.

[65] Iaboni A, Cockburn A, Marcil M, Rodrigues K, Marshall C, Garcia MA, Quirt H, Reynolds KB, Keren R, Flint AJ (2020) Achieving safe, effective, and compassionate quarantine or isolation of older adults with dementia in nursing homes. Am J Geriatr Psychiatry 28, 835-838.

[66] Bentayeb M, Norback D, Bednarek M, Bernard A, Cai G, Cerrai S, Eleftheriou KK, Gratziou C, Holst GJ, Lavaud F, Nasilowski J, Sestini P, Sarno G, Sigsgaard T, Wieslander G, Zielinski J, Viegi G, Annesi-Maesano I, Study G (2015) Indoor air quality, ventilation and respiratory health in elderly residents living in nursing homes in Europe. Eur Respir J 45, 1228-1238.

[67] Adalja AA, Toner E, Inglesby TV (2020) Priorities for the US health community responding to COVID-19. JAMA 323, 1343-1344.

[68] Halsell B, McDonald R, Design for Dementia: Volume 1 - A Guide with helpful guidance in the design of exterior and interior environments.

[69] Lin SY (2017) Dementia-friendly communities' and being dementia friendly in healthcare settings. Curr Opin Psychiatry 30, 145-150.

[70] Turner N, Morken L, Better Together: A Comparative Analysis of Age-Friendly and Dementia Friendly Communities. AARP International Affairs., March 2016.

[71] Alzheimer's Disease International (ADI). Dementia Friendly Communities: Key Principles. Alzheimer's Disease International, http://www.alz.co.uk/DFC,

[72] Fleming R, Zeisel J, Bennett K (2020) World Alzheimer Report 2020: Design, Dignity, Dementia: Dementiarelated design and the built environment Volume 1. Alzheimer's Disease International (ADI). London.

[73] Kalache A, Plouffe L, Purdy K, Netherland J, Krieger A, Finkelstein R, Eve D, Yu W, MacKay J (2007) Global Age Friendly Cities: A Guide. World Health Organization.

[74] UK/England Dementia Friendly Communities. A review of dementia friendly initiatives in the UK. Alzheimer's Disease International. https://www.alz.co.uk/dementiafriendly-communities/england

[75] Alzheimer's Cafe - Dementia Friendly Communities. A review of Alzheimer Cafes and Memory Cafes. Alzheimer's Disease International. https://www.alz.co.uk/ dementia-friendly-communities/alzheimer-cafe

[76] Japan - Dementia Friendly Communities. A review of dementia friendly initiatives in Japan. Alzheimer's Disease International. https://www.alz.co.uk/dementia-friendlycommunities/japan\#Uji

[77] 'Dementia Towns': How Japan is Evolving for Its Ageing Population. The Guardian International Edition. https:// www.theguardian.com/world/2018/jan/15/dementiatowns-japan-ageing-population

[78] Kiyota E (2016) Ibasho: Building Socially Integrated and Sustainable Communities: An Interview with Emi Kiyota. Interviewer: Jean Galiana. Access Health International, New York.

[79] Kiyota E (2018) Co-creating environments: Empowering elders and strengthening communities through design. Hastings Cent Rep 48(Suppl 3), S46-S49.

[80] Case Studies - Dementia Friendly Communities. Alzheimer's Disease International. https://www.alz.co.uk/demen tia-friendly-communities/case-studies
[81] Godwin B (2015) Hogewey: A 'home from home' in the Netherlands. J Dement Care 23, 28-31.

[82] Eloy VH, DeHogeweyk (slide presentation), http://www. bethecareconcept.com, November 2014.

[83] DeHogeweyk in Weesp, Holland: The Dutch village is exclusively for people with dementia. The Loop Website, https://www.theloop.ca/this-dutch-villageis-only-for-people-with-dementia/

[84] The Amazing Village in The Netherlands Just for People with Dementia. Twisted Sifter Website, https:// twistedsifter.com/2015/02/amazing-village-innetherlands-just-for-people-with-dementia/, Accessed February 4, 2015.

[85] Harris J, Topfer LA, Ford C (2019) CADTH Issues in Emerging Health Technologies, Issue 178, Ottawa, Canada.

[86] Haeusermann T (2018) The Dementia Village: Between Community and Society. In Care in Healthcare, Krause F, Boldt J, eds. Palgrave Macmillan, Cham.

[87] Will the US follow Europe's lead of offering entire dementia villages? Some programs such as Glenner Town Square, are underway that could perhaps lead the way toward residential development. Considerable Staff Website, https://www.considerable.com/health/dementia/dementiavillages/, Accessed June 21, 2019.

[88] The Green House Project. Overview of the Green House Project Concept, https://www.thegreenhouseproject.org/ about/visionmission,

[89] Cohen LW, Zimmerman S, Reed D, Brown P, Bowers BJ, Nolet K, Hudak S, Horn S, Collaborative TR (2016) The Green House Model of nursing home care in design and implementation. Health Serv Res 51(Suppl 1), 352-377.

[90] Kary M (2019) BC Care Providers Association, New Care Models: Creating Dementia Friendly Environments in Long Term Care. A Slide Presentation to the Newfoundland and Labrador Centre for Applied Health Research (NLCAHR) Research Exchange Group on Aging.

[91] Rieger S, The 'Butterfly model' transforms this dementia care facility into a real home. A Calgary care facility is one of just a handful of Butterfly Care Homes in Canada. CBC News, https://www.cbc.ca/news/canada/calgary/butterflycare-home-calgary-1.4857933, Accessed October 10, 2018.

[92] Haubenhofer DK, Elings M, Hassink J, Hine RE (2010) The development of green care in western European countries. Explore $(N Y)$ 6, 106-111.

[93] Verbeek H, deBoer B, Hammers J, Green Care Farms as an alternative living arrangement for people with dementia?, https://www.ipa-online.org/news-and-issues/green-carefarms-as-an-alternative-living-arrangement-for-peoplewith-dementia

[94] de Bruin SR, Pedersen I, Eriksen S, Hassink J, Vaandrager L, Patil GG (2020) Care farming for people with dementia; What can healthcare leaders learn from this innovative care concept? J Healthc Leadersh 12, 11-18.

[95] Green Care Farms. New Jersey, United States Green Farms, based on European Models of Green Care, Green Care Farms Website, https://greencarefarms.com/

[96] Eden Principles. 10 principles of Eden Alternative Care. The Eden Alternative Website, http://www.edeninoznz. com.au/html/s02_article/article_view.asp?id=105\&nav_ cat_id $=137 \&$ nav_top_id $=56$

[97] Eden Alternative and Green House Concept of Care: Review of Clinical Effectiveness, Cost-Effectiveness and Guidelines. Health Technology Inquiry Service 
(Canadian Agency for Drugs and Technologies in Health), htis@cadth.ca, March 25, 2010,

[98] Barrett P, Sharma M, Zeisel J (2018) Optimal spaces for those living with dementia: Principles and evidence. Build Res Inform 47, 734-746.

[99] Vinick D (2019) Dementia-friendly design: Hogeweyk and beyond. Br J Gen Pract 69, Page 300.

[100] Howe K, Natural Light May Benefit Dementia Patients, https://absolutetrustcounsel.com/natural-light-may-bene fit-dementia-patients/, Accessed December 11, 2019.

[101] Varvarides P, Tips on Lighting for Dementia, https://www. lighting.co.uk/know-how/tips-on-lig, June 26, 2014 ,

[102] Blais J, Zolezzi M, Sadowski CA (2014) Treatment options for sundowning in patients with dementia. Mental Health Clinician 4, 189-195.

[103] Bachman D, Rabins P (2006) "Sundowning" and other temporally associated agitation states in dementia patients. Annu Rev Med 57, 499-511.

[104] Canevelli M, Valletta M, Trebbastoni A, Sarli G, D'Antonio F, Tariciotti L, de Lena C, Bruno G (2016) Sundowning in dementia: Clinical relevance, pathophysiological determinants, and therapeutic approaches. Front Med (Lausanne) 3, 73.

[105] Hanford N, Figueiro M (2013) Light therapy and Alzheimer's disease and related dementia: Past, present, and future. J Alzheimers Dis 33, 913-922.

[106] Konis K, Mack WJ, Schneider EL (2018) Pilot study to examine the effects of indoor daylight exposure on depression and other neuropsychiatric symptoms in people living with dementia in long-term care communities. Clin Interv Aging 13, 1071-1077.

[107] Wilson S, City Metric: Architecture, https://www.city metric.com/fabric/how-innovative-home-design-couldrevolutionise-dementia-care-and-even-slow-downsymptoms-3945, Accessed June 13, 2018.

[108] Clay J, For Alzheimer's and dementia patients, thoughtful design can have a big impact. USC Architecture Website Article, https://arch.usc.edu/news/for-alzheimers-and-de mentia-patients-thoughtful-design-can-have-big-impact

[109] Calkins MP (2018) From research to application: Supportive and therapeutic environments for people living with dementia. Gerontologist 58, S114-S128.

[110] Kleibusch K (2018) Wayfinding \& dementia: How design can improve navigation among older adults in assistedliving facilities. SPNHA Rev 14, 25-42.

[111] Marquardt G, Bueter K, Motzek T (2014) Impact of the design of the built environment on people with dementia: An evidence-based review. HERD 8, 127-157.

[112] Mitchell DL, Breaking New Ground: The Quest for Dementia Friendly Communities. Housing Learning and Improvement (LIN) Network, http://www.housinglin. org.uk, June 2012,

[113] Fuggle L (2017) Design and dementia: When less is more. $J$ Dement Care 25, 14-15.

[114] Benson S (2002) The use of color in dementia specific design. J Dement Care July/August 2002, 20-23.

[115] Can different colors influence a person with dementia? Here's what to know. The Advocate Website. Alzheimer's Services of the Capital Area care of Dana Territo., https://www.theadvocate.com/baton_rouge/entertain ment_life/health_fitness/article_922b136a-84d5-11e68c00-fbc8ac72b472.html, Accessed October 23, 2016.

[116] Moreno-Martinez FJ, Rodriguez-Rojo IC (2015) On colour, category effects, and Alzheimer's disease: A critical review of studies and further longitudinal evidence. Behav Neurol 2015, 1-12.

[117] Marquardt G (2009) Dementia-friendly architecture: Environments that facilitate wayfinding in nursing homes. $A m$ J Alzheimers Dis Other Demen 24, 333-340.

[118] Marquardt G (2011) Wayfinding for people with dementia: A review of the role of architectural design. HERD 4, 75-90.

[119] Davis R, Weisbeck C (2016) Creating a supportive environment using cues for wayfinding in dementia. J Gerontol Nurs 42, 36-44.

[120] Dyer SM, Liu E, Gnanamanickam ES, Milte R, Easton T, Harrison SL, Bradley CE, Ratcliffe J, Crotty M (2018) Clustered domestic residential aged care in Australia: Fewer hospitalisations and better quality of life. Med J Aust 208, 433-438.

[121] Fleming R, Purandare N, Long-term care for people with dementia: Environmental design guidelines. Research Online (University of Wollongong, Australia). https://ro.uow.edu.au/hbspapers/653

[122] Day K, Carreon D, Stump C (2000) The therapeutic design of environments for people with dementia: A review of the empirical research. Gerontologist 40, 397-416.

[123] Whear R, Coon JT, Bethel A, Abbott R, Stein K, Garside $\mathrm{R}$ (2014) What is the impact of using outdoor spaces such as gardens on the physical and mental well-being of those with dementia? A systematic review of quantitative and qualitative evidence. J Am Med Dir Assoc 15, 697-705.

[124] Gardens and Outdoor Spaces. Victoria State Government Website (health.vic), https://www2.health.vic.gov.au/ ageing-and-aged-care/dementia-friendlyenvironments/gardens-outdoors

[125] Heath Y (2004) Evaluating the effects of therapeutic gardens. Am J Alzheimers Dis Other Demen 19, 239-242.

[126] Lewis S, Dementia and The Built Environment. CIAT Website, https://www.designingbuildings.co.uk/wiki/ Dementia_and_the_built_environment,

[127] Lytle JW, COVID-19 and Nursing Homes: The New York State Experience, https://blog.petrieflom.law.harvard. edu/2020/09/09/covid19-nursing-homes-new-york/, Accessed September 9, 2020.

[128] Condon B, Sedensky M, Hoyer M, New York's true nursing home death toll cloaked in secrecy,AP News, https:// apnews.com/article/ap-top-news-understanding-the-out break-new-york-andrew-cuomo-health-212ccd87924b69 06053703a00514647f, Accessed August 10, 2020.

[129] New York's coronovirus death toll in long-term care homes could be a significant undercount. The Associated Press published by CBC News., https://www.cbc.ca/news/ world/ny-cuomo-coronavirus-nursing-homes-1.5681914, Accessed August 11, 2020.

[130] Nalabandian M, O'Brien J, League A, Ravi S, Meyer D, Snyder M, Mullen L, Warmbrod L, GHS Index: Global Health Security Index - Building Collective Action and Accountability. John Hopkins Bloomberg School of Public Health: Center for Health Security, http::/www. ghsindex.org, October 2019.

[131] Afendulis CC, Caudry DJ, O’Malley AJ, Kemper P, Grabowski DC, Collaborative TR (2016) Green house adoption and nursing home quality. Health Serv Res 51(Suppl 1), 454-474.

[132] Zimmerman S, Bowers BJ, Cohen LW, Grabowski DC, Horn SD, Kemper P, Collaborative TR (2016) New evidence on the green house model of nursing home care: Synthesis of findings and implications for policy, 
practice, and research. Health Serv Res 51( Suppl 1), 475-496.

[133] Bowers BJ, Nolet K (2014) Developing the green house nursing care team: Variations on development and implementation. Gerontologist 54(Suppl 1), S53-64.

[134] de Boer B, Hamers JPH, Zwakhalen SMG, Tan FES, Verbeek H (2017) Quality of care and quality of life of people with dementia living at green care farms: A cross-sectional study. BMC Geriatr 17, 155.
[135] McAllister A, Beaty JA (2016) Aging well: Promoting person-directed care. J Aging Sci 4, 1000164.

[136] Coleman MT, Looney S, O’Brien J, Ziegler C, Pastorino CA, Turner C (2002) The Eden Alternative: Findings after 1 year of implementation. J Gerontol 57A, M422-M427. 